\title{
Product-Counterfeiting can be Controlled in Supply Chains of Automotive Parts Industry
}

\author{
SAAD AKHTER JAFFERY* \\ RECEIVED ON 31.05.2017 ACCEPTED ON 12.02.2018
}

\begin{abstract}
The objective of this paper is to compile information that will help researchers and practitioners to use EFA(Exploratory Factor Analysis) in reference to the relevant anti-counterfeiting strategies in supply chain under deceptive buying environment, in order to make prudent decisions according to the "best industry practices" based on ISO (International Organization for Standardization) available in the automotive industry. Product counterfeiting is a worldwide business issue which effect firm's supply chain (supply chain sustainability) directly or indirectly. The study used a quantitative research design technique where categorical and numerical variables are used to determine relationships among variables where a survey is used as a main research method. Futuristically, the developed instrument using EFA would lead to the CFA (Confirmatory Factor Analysis) to answer questions regarding validity of the instrument in the concerned population subgroups. This empirical study is done after conducting Initial Survey where pilot testing procedure of Initial instrument was followed to make sure that questions asked were good enough (reliability analysis) to capture the impacts of ANCT-INT (Anti-Counterfeiting Strategies Initiative) on the FSP(Firms' Supply Performance). The Pilot test process of Initial Survey Instrument is conducted prior to an actual data collection (confirmatory survey) stage that can helps researcher in refining the confirmatory survey instrument. The pilot test is conducted under the patronage of PAAPAM (Pakistan Association of Automobile Parts and Accessories Manufacturers) secretariat in Lahore. The participants involved are the Automotive Engineering firms practicing as the permanent PAAPAM member firms.
\end{abstract}

Key Words: Anti-Counterfeiting Strategies, Deceptive Buying, Exploratory Factor Analysis, Supply Chain Management.

\section{INTRODUCTION}

I

CC (International Chamber of Commerce) CIB (Counterfeiting Intelligence Bureau) published report OECD [1], discussing the adverse impact of parts and accessories affected the most. The report indicated that counterfeits target cost effective standard parts that can be fitted to different models with shorter counterfeiting in the automotive industry where spare product life cycle and are sold on OTC (Over The Counter)

Authors E-Mail: (saadjaffery@gmail.com)

* Institute of Quality \& Technology Management, The University of Punjab, Lahore.

This is an open access article published by Mehran University Research Journal of Engineering and Technology, Jamshoro under the CC by 4.0 International License. 
level. The worldwide industry has no formal organization devoted to combating counterfeiting (OECD [1]). Big automakers in the world like Ford, GM, Peugeot-Renault, Honda, and Toyota Motors do have in-house anticounterfeiting programs and surveillance teams to address the issue. Even then, the automotive industry suffered overall losses of approximate around US\$ 12 billion on account of sales in unauthorized parts (counterfeits), out of which the USA accounted for US\$ 3 billion and the Europe accounted for largest bearer of a share of remaining US\$ 9 billion (Automotive Marketing [2]). GM of USA believes that they and their suppliers lost approximately US $\$ 1.2$ billion annually from unrealized sales due to counterfeit parts. Peugeot-Renault from France reported that they continuously loosing year-wise between FF 600 and FF 900 million. The countries where large production facilities exists have been named as Spain, Italy and Portugal in Europe, and Taipei, Singapore, Turkey, China, India in Asia (OECD [3]). The OECD (Organization for Economic Co-operation and Development) report further discussed that sub-markets for counterfeit products are primary and secondary markets. In the primary markets, consumers purchase counterfeits under some kind of deception believing that they are purchasing genuine products deceptive buying, (Green and Smith [4]). The counterfeits often found noncompliant against quality standards and carry sever health and safety risks. In secondary market, customers are knowingly purchase counterfeit products (non-deceptive buying), (Green and Smith [4]). The report (Williams et. al. [5]) discussed different driving factors of demand and supply of counterfeit goods. Therefore, many opportunities exist to investigate further, keeping in view a theoretical aspect of counterfeiting phenomenon in supply chain, about contractual obligations, operations and marketing coordination, product risk \& mitigation, quality management, knowledge management, product design and integration during its life cycle, outsourcing and supplier selection, and culture etc. Furthermore, investigative studies should be performed regarding various challenges exist to industry best-practices facing counterfeiting phenomenon and adequate research methods required for that matter.

Theoretical understanding of product counterfeiting and knowledge about various suggested strategies are necessary for researchers and practitioners to control counterfeiting phenomenon in supply chain of automotive industries in Pakistan. A compiled version of anticounterfeiting strategies will provide a clearer picture of sub-categories of product counterfeiting in supply chain research. The literature review suggested the best possible course of action for manufacturer to take recourse both with criminal \& civil action. The law has provided sufficient teeth to deal with counterfeiting in Pakistan. However, the general understanding is that the effort to curb the counterfeiting practices should be initiated by the manufacturer and anti-counterfeiting strategies should be introduced in supply chain operations to create awareness among customers and consumers. The anticounterfeiting strategies suggested by different researchers and experts in three decades, under deceptive buying environment, are now compiled to determine clear structure of commonality in order to strategically control product counterfeiting in supply chains for automotive industries in Pakistan. Factor analysis is an important tool that could help researchers to evaluate tests, to develop \& refine scales and measures that can be used in the context of product counterfeiting phenomenon. Therefore, factor analysis is used for dimensional reduction in an original data set where existing number of common factors captures enough information to clearly 
understand the relevant definition. So, the criteria to determine "variance retained" when converting similar features looks for decomposition into factors (Eigen values), using PCA (Principal Component Analysis).

EFA approach is used to analyze the data collected from automotive industry which could be helpful in capturing clearly marked structure of commonalities to address the said issue. OECD [1] discussed the salient objectives of EFA: (1) number of variables are reduced; (2) the structure and relationship between variables are examined; (3) unidimensionality of the theoretical construct (detection and assessment); (4) the construct validity of a scale should be evaluated and tested; (5) develop parsimonious (simple) analysis and interpretation; (6) Addresses multicollinearity (two or more variables that are correlated); (7) Used to develop theoretical constructs; (8) theories proposed should be either disproved or proved. Williams et. al. [6] and Kieffer [7] discussed that the presence of priori or theoretical rationale to hypothesize a specific factor structure (with some particular items loadings), creates possibility to switch to a CFA approach from EFA. The PCA is only concerned with establishing linear component that exists within the data and how a particular variable may contribute to that component. This technique can be used as: (1) first to understand the structure of a set of variables; (2) second to measure variables a questionnaire needs t be developed; (3) third to maintain manageable data size after factorization while retaining as much of the original information as possible. In multiple-regression, multi-collinearity may be a problem where factor analysis technique is useful by combining variables that are collinear. Broadly speaking there is no expectation on behalf of a researcher about the number or nature of the variables in EFA (more exploration expected). Therefore, EFA technique allows researchers to explore main dimensions in order to generate a theory through a theoretical model with relatively more set of latent constructs represented by determined set of items.

The research study is limited to evaluate anticounterfeiting strategies only, in relation to its number of citations and relative importance (categories), according to clear structure of commonalities and then apply EFA technique to empirically segregate strategies according to its empirically defined measures / categories. The details of the anti-counterfeiting strategies evaluation process, based on the number of citation, have already been discussed in my earlier publication. The publication focused on literature review, encompasses theoretically developed common factors (measuring aspects). This research study approach is to develop understanding among researchers to address an existing gap between theoretically developed factors (measures/categories) and the factors developed through observation. In this way enough information is captured to clearly mark the structure of commonalities (a framework) to address the product counterfeiting issue. Here, this is to be made clear that further empirical investigation about employment cohort citations under the influence of other dimensions like SCMP (Supply Chain Management Practices), TQMP(Total Quality Management Practices), and FSP (Firm Supply Performance) are not under the preview of this research study. This study after clarifying the need of EFA technique application on anticounterfeiting strategies, discussed the importance of Pilot testing, Instrument deployment process for pilot testing, Initial survey process, Data collection and Analysis processes, Content analysis and citations preparation process, Survey instrument design, Survey data description, and other important areas of interests related to EFA application and pilot testing process are

Mehran University Research Journal of Engineering \& Technology, Volume 37, No. 4, October, 2018 [p-ISSN: 0254-7821, e-ISSN: 2413-7219] 
described in the subsequent sections. After discussing the theoretical part of the research study, the empirical part of the EFA technique under five important protocols was discussed. This article comprehensively conclude the important steps of the pilot study regarding suggested anti-counterfeiting strategies which are necessary for researchers and practitioners to control counterfeiting phenomenon in supply chain of automotive industries in Pakistan. Therefore, a compiled version of anticounterfeiting strategies will provide a clearer picture of sub-categories of product counterfeiting in supply chain research.

Bodner [8] studied US defense systems with SCM (Supply Chain Management) practices and revealed that sometime obsolete parts are no longer available in the OEM's (Original Equipment Manufacturer) inventory reserve pool and that gap could become the biggest risk for licit supply chain and performance and failure characteristics of counterfeits shows variation against genuine parts performances and can produce serious adverse impact on product or service availability, reliability, performance and safety issues (Bodner [9]). Santos, and Ribeiro [10] emphasized that strategies should be developed to curb counterfeiting needs and for that matter strong recognition of cultural aspect in this regard is very important. Staake et. al. [11] discussed six main categories in reference to deceptive buying patterns which are focused on interrelationship between the licit and the illicit supply chains, based on major literary contributions concentrated on the word "counterfeits". Staake et. al. [12] revealed counterfeits' trade is considered as trillion dollar industry directly or indirectly affecting wide range of goods and licit trades. His study discussed the existing efforts put forward against different groups of counterfeiters, such as: Dis-aggregators; Imitators; Fraudsters; Desperados;
Smugglers. He encourages researchers and practitioners to study further to bring resolve to this problem. For licit and illicit trade phenomenon, D'Amato and Papadimitriou [13] and Staake et. al. [11] have analyzed different trades under different supply chain conditions: (1) pure counterfeiting; (2) factory overruns; (3) grey and parallel markets; (4) supply chain infiltration; (5) product diversion; (6) sale of stolen goods. The study develops understanding about which supply chain (legitimate or illegitimate) interactions are most damaging to effectively counter counterfeiting activities. Chaudhry and Zimmerman, [14], Chaudhry et. al. [15], and Eser et. al. [16] discussed the IPR importance and recommended some strategies to counter counterfeiting activities. Yang et. al. [17] states "because of the prevalence of counterfeiting, multinationals should be solution-oriented and treat counterfeiting as a daunting challenge rather than an affliction, and suggested using a combination of the ten strategies as the most effective approaches". Stevenson and Busby [18], Wilcock and Boys [19], and Verma et. al. [20] discussed the importance of anti-counterfeiting efforts, demand-side and supply-side driving factors and suggested some strategies to establish quality control in supply chains in organizations. Moreover, the US Chamber of Commerce CACP (Coalition Against Counterfeiting and Piracy and Accenture) [21] published a report followed best practices to minimize the risk of counterfeiting in supply chain: secure legitimate input; verify legitimacy of customers and distributors; production waste management and damaged / unusable inventory management; ensures legitimacy of licit products purchased at retail outlet; monitor brand integrity; outreach to law enforcement and regulatory officials. Limited number of studies have investigated the upstream activities of the illegitimate supply chain and described the main characteristics of the possible actors

Mehran University Research Journal of Engineering \& Technology, Volume 37, No. 4, October, 2018 [p-ISSN: 0254-7821, e-ISSN: 2413-7219] 
(OECD [1]) at different stages of product counterfeiting, Grey imports (product diversion), illegitimate trade activity (supply chain infiltration), Retail service copycatting, shop lifting, and factory overruns. Many automotive companies are deeply concerned with the problems of large scale product counterfeiting activities observed in supply chains. The theoretical aspect forced researchers and practitioners to explore further into the occurrences of counterfeiting phenomenon in supply chains of automotive industries in reference.

\subsection{Pilot Testing}

The instrument (questionnaire) is tested through a pilot testing process which is an important component of data collection process. A pilot testing is a small scale trial-run that serves the main research purpose of the study. A pilot test can provide sufficient details about the respondents which are not available before. It can capture enough responses needed to complete the necessary representative survey and proves to be very effective in establishing content and face validity. Therefore, researchers need to be clear about addressing various question of the pilot testing instrument, such as: (1) what to pilot test; (2) why to pilot test; (3) when to pilot test; (4) who to be tested (participating groups); (5) how to conduct test. In a literature review process while investigating the facts about addressing the referenced questions, it was discovered that Alotaibi [22] did some investigative work in the field of Information technology and addresses the referenced questions in his field of interest by following the instrument's pilot testing process in a comprehensive manner. His research topic was "Extending and validating the IS-impact model in Saudi Arabia: Accounting for computer network quality", available in the repository of the Queensland University of Technology, Australia. Considering the valuable nature of his work, the present research work encompasses some important inferences from his research specific to the "Instruments Pilot testing process" and applied pilot testing steps in automotive industries of Pakistan, in the concerned area of research domain. However, ideas from other investigative work in reference to pilot testing procedures have also given due weight-age. The objective of this research study is to develop understanding about an existing gap between theoretically developed factors (measures/categories) and the factors developed through observations (supported by pilot survey). As a consequence, after addressing this gap, enough information is available to formulate common anticounterfeiting strategies to counter the product counterfeiting issue. Fink and Kosecoff [23] discussed that the survey instrument must undergo a pilot test. Straub [24] and Bagozzi [25] discussed that the initial design of the instrument is finalized through pilot testing activities so to implement confirmatory survey instrument. And, the result of these activities will finalize the confirmatory survey procedure.

\subsection{Initial Survey Instrument}

The initial survey instrument, in pilot testing, provides insight to researcher to apply the Confirmation Survey successfully with required changes and in this way avoid instrument's shortcomings. The modification of the instruments after pilot test starts from the design aspects of the survey instrument. The instrument covers all aspects related to face $\&$ content validity of an instrument (content analysis, content analysis procedure, execution of the process (pilot test objectives, test procedures (data collection (instrument design, instrument pilot test, conducting workshops, instrument dissemination), data description and responses), survey findings (mapped \& unmapped citations)). Interested readers can collect

Mehran University Research Journal of Engineering \& Technology, Volume 37, No. 4, October, 2018 [p-ISSN: 0254-7821, e-ISSN: 2413-7219] 
further information from the author related to the topics discussed earlier in development of this initial survey instrument. In this regard, workshop and seminar can be very helpful in enhancing face and content validity of the instrument. However, I will discuss here the procedure executed in the pilot test just because of its importance

\subsection{Procedure Executed in the Pilot Test}

There are procedural aspects of the pilot test of the survey instrument that covers PAAPAM member organizations in Pakistan.

\subsubsection{Initial Survey Instrument}

There are two sections in the Initial survey instrument. Initial section covers information about organization, demographic and personal data about the participants. The section contains: type of businesses; type of operations, number of ISO \& other standards; management practices followed; experience of QM (Quality Management) system applications; turnover; employee strength; respondent position, education, number of years supply chain experience under TQM and SCM environment. While, the second section of the Initial survey instrument raises a direct question about the impacts of TQM \& SCM practices on FSP and likewise the impact of Anti-Counterfeiting strategies initiatives on FSP.

\subsubsection{Pilot Test Objectives}

The pilot test objective is to help respondents to disseminate the desired information within an instrument as comprehensively (with face and content validity) as possible. The pilot test of initial survey instrument provides insight about the expected response rate, teething problems in data collection, and different research methods used for that matter.

\subsubsection{Pilot Test Procedure}

The pilot test procedure takes two phases to complete and every outcome is assessed through subsequent workshops. Every workshop analyzes the findings of the pilot study so to make appropriate adjustments in the design of the survey instrument. In this way, preemptive refinements in the design of the Confirmatory Survey Instruments could be administered successfully. Initially, the pilot test was performed with the help of PAAPAM secretariat at Lahore office where supply chain practitioners and procurement decisions makers, from automotive industry, participated in one of the training program organized by PAAPAM.

In the first phase the survey instrument is introduced among the participants, asking them to express their views about the quality of the instrument and raised inquiry about improvement of the design of the format of the instrument, suitability of terminologies and content used to speed up the response rate of fulfillment. For that matter, a workshop was organized where university experts are invited to discuss the instrument and required understanding about its items. The overall outcome of the first round of a pilot survey is proved very successful, some modifications in wording of the items takes place. The clearer instructions are in place before the start of every section of the instrument in order to facilitate respondents to respond accurately against each item.

In the second phase the participants of automotive organizations (Pak Suzuki, Honda, and Toyota) are introduced. The meeting is conducted in person so to have better and quick response. The participants' suggestions are sought to improve understandability of the items and appearance (face validity) of the instrument in order to achieve better response rate. For that matter a

Mehran University Research Journal of Engineering \& Technology, Volume 37, No. 4, October, 2018 [p-ISSN: 0254-7821, e-ISSN: 2413-7219] 
guideline is used for respondents to respond quickly. Few problems and remedies are discussed at this forum along with some recommendations on the final survey instrument design. Likewise, the incomplete or partially complete status of any instrument has potential to cause problem in respond to number of usable responses. The mandatory requirements are to be incorporated as design consideration of any instrument. Web based surveys could be used for that matter to easily fulfill these enforcement requirements. The traditional paper based instrument, however, does not comply in a regular fashion with these enforcement requirements. To overcome such problems, heads of the organization can direct their employees to respond clearly and completely so that their responses could be reviewed thereafter for further clarification. In this way, the respondents' unrealistic responses could be limited. English language and translation problems attached with the instrument can also be highlighted during the pilot test. Therefore, the final version of the survey instruments can be used for confirmatory survey. The pilot test procedure covers initial survey data collection, initial survey data description, and initial survey findings.

\subsubsection{Initial Survey Data Collection}

The initial data collection process takes cares initial survey instrument design, survey instrument pilot test, subsequent workshop on survey instrument for further refinement, and then comes the instrument dissemination. Here, the participating organizations at PAAPAM platform can be very instrumental in disseminating the survey instrument's information

\subsubsection{Initial Survey Instrument Design}

The first section of the questionnaire is designed for collecting personal and demographic information about the respondents. The information contain: type of businesses and operations; number of ISO and other standards; management practices followed; experience of QM system applications; turnover; employee strength; respondent position, education, number of years of working experience in environments like: TQM and SCM environments. In the subsequent section direct questions are asked about the impacts resulting from the SCQM (Supply Chain Quality Management) construct and ANCT-INT construct on the FSP.

In the next section, the initial survey poses specific and direct questions. Its aim is to gather the impact of SCQM approach. One of an open question is "what do you consider have been the significant impacts of TQM and SCM practices on firms under the influence of SCQM approach?". This open question welcomed positive and negative impacts on firms' response to its cohort. Before each question to be answered, there is a brief description of the objectives of the questions which may have helped respondents to address question. There is a possibility to add another question to capture the respondents' perception about the quality of the implementation of the management systems in their firms but that possibility was later ruled out. The reason was to encourage the respondents to respond freely without any limitations. Likewise, the other open question is "what do you think, how anti-counterfeiting strategies within supply chain can reduce the occurrences of counterfeiting phenomenon?". This question welcomes suggestion from practitioners, procurement specialists, and educationists to formulate appropriate anti-counterfeiting strategies which could address the referenced issue. However, in initial survey some close questions are also present which are related to "anti-counterfeiting initiatives" where respondents are asked to select their preferred choices (based on Likert scale) in order to ascertain the level of

Mehran University Research Journal of Engineering \& Technology, Volume 37, No. 4, October, 2018 [p-ISSN: 0254-7821, e-ISSN: 2413-7219] 
importance in the eyes of practitioners in reference to the mentioned anti-counterfeiting strategies. The survey disseminated manually by the researcher at PAAPAM secretariat at the time of first quarterly members meeting in 2016, with a chance to create awareness among the audience about the significance of the research study. Respondents are encouraged to respond accurately (quality responses) according to respondents' background.

The exploratory work can be done by conducting interviews with practitioners and experts of PAAPAM member firms, in order to gather required information. Almost, the same questions were asked in the guideline to gather their responses. Use of Interview Guideline: The suggestion/ratification sessions were organized in Pak-Suzuki Motors, Honda Motors and Toyota Motors in Pakistan. The interview sessions were arranged with the participants and for that matter interview guideline was prepared.

\subsubsection{Survey Instrument Pilot Test}

The pilot testing helps in identifying the best method to disseminate the information, where three major area of focus are of immediate concern: collection of needed data through well designed instrument; language used to disseminate information. The purpose of initial survey is to highlight influential dimensions/impacts of ANCT-INT and SCQM on the FSP. Here, the important aspect of the instrument is to make sure that questions are asked are good enough to hold the information about the impacts of the ANCT-INT and SCQM on the FSP. The pilot tests were held under the patronage of PAAPAM where some of its member (60) organizations participated in the Initial Survey. These member organizations were communicated the importance of the topic with reference to the automotive industry and were asked to cooperate to respond to the questionnaire's requirements so that the research problem could be addressed. The concerned organization communicated the same to their managers to endorse the survey to provide quality responses. As English is the official language of Pakistan, so the respondents faced no difficulty in responding to the questionnaire. The strong feedback mechanism (workshops, etc.) improves the appearance of the instrument and helps in redesigning of the survey instrument which is yet another way of developing final version of the survey instrument for confirmatory survey

\subsubsection{Workshops on Survey Instruments}

As a strategy, workshops are organized in a regular interval before the start of the initial survey.

\subsubsection{Instrument Dissemination}

For the dissemination part, the outcome of the different workshops suggests that electronic mail (email \& online survey) through different sources of virtual communication may not be helpful as a means of disseminating the survey instrument information. In Pakistani context, emails and online surveys have never been an attractive option for data collection. In Pakistani context, interactive face-to-face communication is highly preferable over other means. The patronage of the PAAPAM association, in spare parts and automotive industry, facilitated this research study and made Initial Survey possible. The questionnaires were distribution at the end of the PAAPAM sessions ( 3 in numbers) with brief explanation of the need and relevance of the problem to the automotive industry together with the ultimate outcome benefiting the industry in return were also highlighted. The remaining questionnaires for pilot testing

Mehran University Research Journal of Engineering \& Technology, Volume 37, No. 4, October, 2018 [p-ISSN: 0254-7821, e-ISSN: 2413-7219] 
were then filled out through personal visits to different member organizations using proper official channel. For that matter, the request/introductory letters issued by the department of the University were used for official referenced correspondences with PAAPAM and their member organizations.

\subsubsection{Initial Survey Data Description}

Conclusive description of responses covers the citations which are later classified according to their relevance. The process covers description of respondents and responses.

\subsubsection{Description of Respondents}

In this process the descriptions of the respondents are classified according to their demographic data showing different level of employment cohort and their levels of work experience in different departments of a firm. The number of respondents (300 in numbers from 60 firms), representing members of PAAPAM, with an average of 5 participants per firm are requested to participate in the Initial Survey [employment cohort: operational (160), technical (60), strategic (80)]. These three categories of employment cohort were inferred from the participant's occupation/Positions and were in the context of FSP. This brings the limitation to conduct EFA analysis part where sample size must be greater than 255 otherwise KMO (Kaiser-Meyer-Olkin) and Bartlett's tests for measuring sampling adequacy and sphericity respectively will not be conducted. The SPSS will not perform the analysis and print a message "Correlation matric is NPD (NonPositive Definite) appears forcing researcher to adjust the sample size accordingly. This means that some of the Eigen values of correlation matrix are not positive numbers. In employment cohort, the operational category represented by supply chain practitioners $\&$ procurement specialists; the technical category represented by production \& operations managers, Stores \& Inventory Control and Managerial Coordinators; the strategic category represented by the F\&A, CEO and Directors of the company. Department-wise details will cover number of respondents for initial survey from CEO\& Directors (60), Finance \& Accounts (20), Purchase/Procurement specialists (140), Production \& Operations (30), Stores \& Inventory Control (20) and Managerial Coordinators (30). The criteria of selected participants are experts in multinational OEMs/Assemblers, ISO certified supplier $\&$ distributor (upstream intermediaries) companies, members of the automotive associations, government authorities and agencies who are confronted with counterfeiting to collect their specific knowledge. The selected participants must have more than five year experience in supply chains in automotive industry in Pakistan.

\subsubsection{Description of Responses}

In this process the citations are collected so that the impact of SCQM and anti-counterfeiting scale over FSP could be determined. The survey responses (translations) from the instrument are found to be collected in the form of paragraphs. As a primary step, these paragraphs are decomposed into independent units/citations during data analysis portion of the initial survey. The outcome of the workshop leads to confirmation that the citations encompass the relevant SCQM and anti-counterfeiting strategies over FSP. Thus the research objective can be achieved with two methods. One method was conducting interviews with experienced practitioners and managers of Pak-Suzuki Motors, Honda Motors, and Toyota Motor companies for their suggestions and thoughts in accordance with the interview guideline. Their interviews were then recorded, thematically coded, and translated into citations. The second method is to add two direct

Mehran University Research Journal of Engineering \& Technology, Volume 37, No. 4, October, 2018 [p-ISSN: 0254-7821, e-ISSN: 2413-7219] 
questions in the Initial Survey asking the respondents to talk open comments about the impacts of the SCQM and anti-counterfeiting scale over FSP, based upon their experience. The process of decomposition leads to 360 distinct citations (300 were paper based and 60 were interviewee based) on the impacts of the SCQM and anticounterfeiting scale over FSP. The whole exercise has resulted into an average of about 1.2 citations per respondent (over 300 participants).

\subsubsection{Initial Survey Findings}

The accumulated data represents 300 responses which are segmented to yield 360 citations. The method is used to analyze these citations are qualitative deduction content analysis. Decisions for dropped or retained measures of research model are taken after completing the citation mapping procedures. The final measures are categorized as instantiated or non-instantiated or overlapped. However, the unmapped citations are helpful in introducing new measures for the model in the present study context.

\subsubsection{Mapped Citations}

The overall scenario indicates that there are 293 mapped citations which are identified out of 360 citations. This makes $81 \%$ citations which is actually a high account of the citations, shows higher percentage of capturing perceptions of the respondents. There are four dimensions in the model which are displayed in the table. The highest percentage of citations $(54.6 \%)$ is received by TQMP dimensions. While, the SCMP and ANCT-INT dimensions received the moderate percentage of citations; that is $18.7 \%$ and $11.9 \%$ respectively. Each dimension demonstrates its applicability or importance through an index. The lowest percentage of citations (5.4\%) is received by FSP dimension (Table 1).

The details are linked with the details of the employment cohort where citations are linked with each cohort. Few cohort shows greater emphasis on certain dimensions of the model. The overall scenario indicates $55 \%$ of the citations received from Employment Cohort are related to TQMP which is the highest citation ratio as compare to SCMP, ANCT-INT, and FSP. Within a TQMP dimension of an employment cohort, $43.5 \%$ of the citations received from operational staff. Whereas, $12 \%$ of the citations received from Employment Cohort were related to ANCTINT which was the lowest citation ratio as compare to TQM, SCMP, and FSP. Within ANCT-INT dimension of an employment cohort, $43 \%$ of the citations received from the Technical cohort. As long as the FSP reference is concern the table shows that only strategic cohort received citations $(46.5 \%)$. While, other cohorts have different percentage of citations shows participant's perceptions about these measures. Therefore, the lowest citations ratio of ANCT-INT dimension indicates respondents' unawareness status regarding the potential business issue, that is, the presence of the product counterfeiting phenomenon in supply chains of automotive industries in Pakistan (Table 2).

TABLE 1. MODEL DIMENSIONS AND CITATIONS DETAIL

\begin{tabular}{|c|c|c|}
\hline Model Dimensions & No. of Citations & Citations (\%) \\
\hline Supply Chain Management Practices & 55 & 18.7 \\
\hline Total Quality Management Practices & 160 & 54.6 \\
\hline Anti-Counterfeiting Strategies Initiative & 35 & 11.9 \\
\hline Firm's Supply Performance & 43 & 5.4 \\
\hline Total & 293 & 100 \\
\hline
\end{tabular}

Mehran University Research Journal of Engineering \& Technology, Volume 37, No. 4, October, 2018 [p-ISSN: 0254-7821, e-ISSN: 2413-7219] 


\subsubsection{Unmapped Citations}

The study indicates that 290 out of the 360 citations are mapped against every measure of the research model. The remaining 70 unmapped citations (which is $20 \%$ of the total citations) require more investigation in order to add further into the model. The fact of the matter is that the unmapped citations (60 out of 70) are found relevant to address survey questions. For example a respondent stated the following: "Counterfeiting phenomenon does occur in supply chains in automotive industry", which is relevant to original model discussed in the $\mathrm{PhD}$ thesis dissertation. The remaining citations are mapped to a specific measure. Only two out of seventy citations (2 out 70) are found irrelevant where operational cohort is totally unaware about the influence of inter-relationship ofTQM \& SCM practices on FSP. For example: "I am not using SCM practices along with TQM during procurement". Eight citations out of seventy (8 out 70) are found too broad to be mapped to a specific measure. So, sixty (60) unmapped citations are found relevant and related to the SCQM Impact construct. These citations are then analyzed using the inductive approach. The results of the analysis help the derivation of one of several distinct category "theme", linking to "anti-counterfeiting strategies initiative". Different categories of the unmapped citations are discussed as shown in Table 3.

A workshop was conducted to investigate the theme and inter-relationship to ANCT-INT and SCQM impact on FSP. Several themes derived from the analysis of the unmapped citations towards ANCT-INT are then account for as a construct that represent salient strategies which are necessary to reduce counterfeiting phenomenon in supply chains for automotive industries in Pakistan. Moreover, the suggestive literature reviews regarding compiled form of suggestive anti-counterfeiting strategies regarding negative effect of product counterfeiting on organizations and economies can also consider as the causes of the emergence of the ANCT-INT construct in this study. The recommended table of the anticounterfeiting strategies (Table 4) is an outcome of the earlier study performed under the title "Strategies to Control Product Counterfeiting in Supply Chain: Literature Review". Both the articles (present and the referred one) are the resulting outcome of the $\mathrm{PhD}$ thesis dissertation efforts. In the referenced Table 4 a compiled form of strategies (31 in numbers) are recommended for further confirmation analysis.

\section{FIVE STEPS TO IMPLEMENT EFA TECHNIQUE}

Step-1: Is the Data suitable for Factor Analysis? Sample Size: The literature still speechless about the presence of any rule of thumb regarding sample size for exploratory factor analysis. Studies have revealed, Fabrigar et. al.

TABLE 3. DETAIL OF UNMAPPED CITATION

\begin{tabular}{|c|c|}
\hline Category & Number of Measures \\
\hline Citation is Irrelevant & 2 \\
\hline Citation is Too broad & 8 \\
\hline Citation is Relevant & 60 \\
\hline Total number of unmapped citations & 70 \\
\hline
\end{tabular}

TABLE 2. EMPLOYMENT COHORT WITH RESPECT TO THEIR CITATIONS DETAIL

\begin{tabular}{|c|c|c|c|c|c|}
\hline Employment Cohort & No. of Citations & SCMP & TQMP & ANCT-INT & FSP \\
\hline Strategic & $80(27.3 \%)$ & $10(18 \%)$ & $40(25 \%)$ & $10(28.5 \%)$ & $20(46.5 \%)$ \\
\hline Technical & $90(30.7 \%)$ & $15(27 \%)$ & $50(31.5 \%)$ & $15(43 \%)$ & $10(23 \%)$ \\
\hline Operational & $123(42.0 \%)$ & $30(55 \%)$ & $70(43.5 \%)$ & $10(28.5 \%)$ & $13(30.5 \%)$ \\
\hline Total & 293 & $55(19 \%)$ & $160(55 \%)$ & $35(12 \%)$ & $43(14 \%)$ \\
\hline
\end{tabular}

Mehran University Research Journal of Engineering \& Technology, Volume 37, No. 4, October, 2018 [p-ISSN: 0254-7821, e-ISSN: 2413-7219] 
[26] and McCallum et. al. [27], adequate sample size is partly determined by the nature of the data. In factor analysis, strong data means strong variable loading and presence of uniformly high communalities without any cross-loading. There may be three possible problems that emerge in the data and can be resolved by maintaining

TABLE 4. REFERRING STRATEGIES TO CONTROL PRODUCT COUNTERFEITING IN SUPPLY CHAIN

\begin{tabular}{|c|c|}
\hline Code & Theme-1: Contractual Binding with Suppliers \\
\hline A-CTFIN-IFT-13 & $\begin{array}{l}\text { Strategies to prohibit counterfeit products, Introduce Strict Liability concept, Return of outsourced technology and product, Ensure } \\
\text { authenticity of material and components, Use of track \& trace technologies, Vigilant to control supply chain risk, } \\
\text { Lean management, Sharing information with suppliers, dealers and retailers }\end{array}$ \\
\hline A-CTFIN-IFT- 8 & $\begin{array}{l}\text { Supplier should consider product/service features that are difficult to replicate and/or easy to distinguish from } \\
\text { those of non-legitimate producers during product development/ improvement. }\end{array}$ \\
\hline A-CTFIN-IFT- 12 & $\begin{array}{l}\text { Cooperation across supply chain, Supplier qualification, Supplier penalties for counterfeits and pass-through, } \\
\text { Making product replication difficult and costly }\end{array}$ \\
\hline A-CTFIN-IFT-9 & Destruction process for obsolete products and components \\
\hline A-CTFIN-SP-1 & Follow Industry Standards for Inspection and Acceptance in open market \\
\hline & Theme-2: Campaign against Product Counterfeiting \\
\hline A-CTFIN-IFT-1 & $\begin{array}{l}\text { Dealing with Customs and law enforcement agencies with the use of track \& trace technologies by: } \\
\text { Lobbying for more rigorous counterfeit controls, e.g. Products attributes and Packaging }\end{array}$ \\
\hline A-CTFIN-IFT-2 & $\begin{array}{l}\text { Dealing with market institutions and industry groups by: Lobbying for more rigorous counterfeit controls, } \\
\text { e.g. forming alliances and networks \& Joint advertisements }\end{array}$ \\
\hline A-CTFIN-SP-9 & Warn distributors and retailers about possible penalties using counterfeits \\
\hline A-CTFIN-IFT-5 & $\begin{array}{l}\text { Advertising about the safety, performance and financial risks associated with counterfeits and } \\
\text { financial incentives for channel members to reject counterfeits }\end{array}$ \\
\hline A-CTFIN-IFT-3 & $\begin{array}{l}\text { Discourage product counterfeiting with the goal of increasing the business and legal risks and making } \\
\text { counterfeiting / Imitation costly }\end{array}$ \\
\hline \multicolumn{2}{|r|}{ Theme-3: Create Awareness against Product Counterfeiting } \\
\hline A-CTFIN-SP-5 & $\begin{array}{l}\text { Strategic contribution to protect IP and implement best industry specific strategies } \\
\text { to curb product counterfeiting phenomenon }\end{array}$ \\
\hline A-CTFIN-SP-3 & Develop Training Material \\
\hline A-CTFIN-SP-4 & $\begin{array}{l}\text { Educate all Stakeholders regarding the product counterfeit phenomenon and serious issues related to it, } \\
\text { especially employees, customers, authorities, law enforcement agencies and others }\end{array}$ \\
\hline A-CTFIN-IFT-6 & Introduce Public Awareness Program \\
\hline A-CTFIN-SP-7 & $\begin{array}{l}\text { Collaborative strategies, sharing intelligence of product counterfeiting activities with authorities and } \\
\text { law enforcement agencies }\end{array}$ \\
\hline A-CTFIN-IFT-4 & Develop centralized distribution network \\
\hline \multicolumn{2}{|r|}{ Theme-4: Formulate Programs to Control Product Counterfeiting } \\
\hline A-CTFIN-IFT-7 & Process of investigation to address complaints \\
\hline A-CTFIN-IFT-10 & Collaboration and Joint Venture \\
\hline A-CTFIN-IFT-11 & Develop Internal Resources and Invest in IPR protective countries \\
\hline A-CTFIN-IFT-14 & Alter product characteristics \\
\hline A-CTFIN-IFT-15 & Loss Prevention and Audit Programs \\
\hline A-CTFIN-SP-16 & Product Disposal Program \\
\hline A-CTFIN-SP-2 & Supplier Audit Program \\
\hline A-CTFIN-SP-6 & Formulate Crisis Management Plan and Surveillance Program \\
\hline A-CTFIN-SP-8 & Joint-Anti-Counterfeiting Action Plan \\
\hline A-CTFIN-SP-10 & Use of Product Track \& Trace Technologies \\
\hline A-CTFIN-SP-11 & Develop Risk Management Plan \\
\hline A-CTFIN-SP-12 & Quality Assurance Program \\
\hline A-CTFIN-SP-13 & Legal action \\
\hline A-CTFIN-SP-14 & Certified Retailer Program \\
\hline A-CTFIN-SP-15 & Do nothing \\
\hline
\end{tabular}

Mehran University Research Journal of Engineering \& Technology, Volume 37, No. 4, October, 2018 [p-ISSN: 0254-7821, e-ISSN: 2413-7219] 
larger sample size. As the generalizability or replicable results are unlikely if the sample is too small. Tabachnick et. al. [28] discussed as a sample size should be more than or equal to 300 responses are needed to perform factor analysis. Furthermore, the sample sizes if equal to 100 then it is considered as poor, if equal to 200 is considered as fair, if equal to 300 is considered as good, if equal to 500 is considered as very good, and if equal to 1000 is considered as excellent Comrey and Lee [29] and Velicer and Fava [30]. There are observations/problems that need to be discussed as follows;

As per item, structure of communalities are considered high if they are $>=0.8$ Velicer [30] and Velicer et. al. [31]. In social sciences, common magnitudes of items when values reaches from $0.4-0.7$. There may arise two possibilities if communalities found less than 0.4. Either item is not related to other items and should be deleted, or included additional factor (explored) for future research.

As a rule of thumb, the minimum loading of an item Tabachnick et. al. [28] should be 0.32 or above which covers approximately $10 \%$ overlapping variance with other items in that factor (cross loading items). The researcher has to decide whether to keep cross loading items or remove them from analytical process, which may be considered as a good choice in the presence of strong loaders ( 0.5 or above) on each factors. There may exists some sizeable cross loaders due to the very reason that items were prematurely written and were not aligned according to a particular inquiry or a priori factor structure may be flawed.

Situation where less than three items when representing a factor is generally considered as unstable or weak. On the other hand, Five (5) or more strongly loaded items are desirable and indicated as a solid factor.
Sample to Variable Ratio: Fabrigar et. al. [26], McCallum et. al. [27] and Tabachnick et. al. [28] studies recommended range anywhere from $3: 1,6: 1,10: 1$, and $15: 1$ or $20: 1$ where "good factor recovery", across different conditions examined, could be reached (Table 5).

TABLE 5. DESCRIPTIVE STATISTICS DETAILS IN RELATION TO ANTI-COUNTERFEITING STRATEGY

\begin{tabular}{|c|c|c|}
\hline \multicolumn{3}{|c|}{ Descriptive Statistics } \\
\hline Dimensions & Mean & $\begin{array}{c}\text { Standard } \\
\text { Deviation }\end{array}$ \\
Analysis N \\
\hline A-CTFIN-IFT-1 & 4.36 & 0.687 \\
\hline A-CTFIN-IFT-2 & 4.35 & 0.685 \\
\hline A-CTFIN-IFT-3 & 4.29 & 0.649 \\
\hline A-CTFIN-IFT-4 & 4.29 & 0.647 \\
\hline A-CTFIN-IFT-5 & 4.29 & 0.643 \\
\hline A-CTFIN-IFT-6 & 4.31 & 0.634 \\
\hline A-CTFIN-IFT-7 & 4.01 & 0.828 \\
\hline A-CTFIN-IFT-8 & 4.28 & 0.677 \\
\hline A-CTFIN-IFT-9 & 4.26 & 0.675 \\
\hline A-CTFIN-IFT-10 & 4.23 & 0.716 \\
\hline A-CTFIN-IFT-11 & 4.15 & 0.753 \\
\hline A-CTFIN-IFT-12 & 4.18 & 0.729 \\
\hline A-CTFIN-IFT-13 & 4.22 & 0.708 \\
\hline A-CTFIN-IFT-14 & 4.34 & 0.688 \\
\hline A-CTFIN-IFT-15 & 4.13 & 0.819 \\
\hline A-CTFIN-SP-1 & 4.21 & 0.772 \\
\hline A-CTFIN-SP-2 & 4.30 & 0.636 \\
\hline A-CTFIN-SP-3 & 4.24 & 0.761 \\
\hline A-CTFIN-SP-4 & 4.34 & 0.683 \\
\hline A-CTFIN-SP-5 & 4.27 & 0.735 \\
\hline A-CTFIN-SP-6 & 4.28 & 0.729 \\
\hline A-CTFIN-SP-7 & 4.27 & 0.735 \\
\hline A-CTFIN-SP-8 & 4.34 & 0.683 \\
\hline A-CTFIN-SP-9 & 4.17 & 0.799 \\
\hline A-CTFIN-SP-10 & 3.78 & 0.721 \\
\hline A-CTFIN-SP-11 & 3.80 & 0.708 \\
\hline A-CTFIN-SP-12 & 4.10 & 0.429 \\
\hline A-CTFIN-SP-13 & 4.13 & 0.420 \\
\hline A-CTFIN-SP-14 & 4.15 & 0.358 \\
\hline A-CTFIN-SP-15 & 4.24 & 0.428 \\
\hline A-CTFIN-SP-16 & 3.75 & 0.871 \\
\hline
\end{tabular}

Mehran University Research Journal of Engineering \& Technology, Volume 37, No. 4, October, 2018 [p-ISSN: 0254-7821, e-ISSN: 2413-7219] 
Factoring Correlation Matrix: EFA upholds a correlation matrix which is used to display the relationships between individual variables. As per the discussion of Tabachnick et. al. [28] and Hair et. al. [32], recommended inspection of the correlation matrix where categorizations of the loadings could be done as $>=0.3$ is considered as minimal, $>=0.4$ is considered as important, and $>=0.5$ is considered as practically significant. In case if correlation is found less than 0.3 , then researcher should think twice using factor analysis as an appropriate statistical. This means that the factor accounted for less than $30 \%$ relationship within the data, or in other words 3rd part of the variable share variance and became nearly impractical for establishing multi-collinearity in the data. On the other hand, the correlation coefficients whose values exceed higher limit (greater than 0.9) indicate possible presence of multi-collinearity in the data. Andy Field discussed that the top half of the table of the Pearson Correlation Coefficient shows certain pattern of relationship where variability in scores (variance) are considered, if necessary, eliminate those variables that do not meet the set criteria. The Tables 6-7 shows data which are investigated \& checked (variable retained if $X>=0.3$ or eliminated if $X>0.9$ ) and found that variables (ACTFINIFT4, ACTFINIFT-7, ACTFINIFT-10, ACTFINIFT-11, ACTFINIFT-14, ACTFINIFT-15, ACTFINSP-2, ACTFINSP-8, ACTFINSP-10 to 16) do not qualify according to the said criteria and should be deleted with the knowledge that those variables may cause problem during future analysis. Therefore, the remaining variables for analysis are considered for further study: ANCTFINT1, ACTFINIFT-2, ACTFINIFT-3, ACTFINIFT-5, ACTFINIFT-6, ACTFINIFT-8, ACTFINIFT-9, ACTFINIFT12, ACTFINIFT-13, ACTFINSP-1, ACTFINSP-3, ACTFINSP-3, ACTFINSP-5, ACTFINSP-6, ACTFINSP-7, and ACTFINSP-9.

The study has performed preliminary analysis to test the suitability criteria.
Checked the descriptive statistics for each variables and checked number of missing cases

Checked the correlation matrix to ensure that it is "Positive Definite", as eigenvalues and matrix determinant should be positive (issues like Singularity may occur).

Checked the Pearson correlation coefficient to determine whether variables are poorly, moderately, or strongly correlated (one-tailed significance of these coefficients, etc.)

Checked the matrix for correlation coefficients for greater than 0.3 and also checked for greater than 0.9 to handle multi-collinearity problem in the data

Use the determinant of the matrix to apply Haitovsky's test just to check whether determinant is zero or not. (variables $=31$, sample size $=300$, Determinant $=1.965 \mathrm{E}$ 006 which should be higher than the necessary value of $0.00001)$

$[\mathrm{X} 2 \mathrm{H}=[1+((2 \times 31+5) / 6)-300] \ln (1-0.000001965)]=(-287.84)$ $* \ln (0.999998035)=0.00056560615$ and shows that the resultant value is other than zero.

The test statistics has degree of freedom $=31(31-1) / 2=465$. Checked the DF @p=0.05 in critical value chi-square table $=447.63(\mathrm{DF}=400)$ and $553.13(\mathrm{DF}=500)$. Both the cases observed much smaller Chi-square value than values indicating non-significance (means that the determinant is not significantly different from zero). Contradictory evidences report presence of multicollinearity in the data. However, applying PCA technique will eliminate possibility of multi-collinearity in the data.

Checked anti-image matrices for MSA (Measure of Sampling Adequacy), where diagonal elements should be greater than 0.5 for all variables. The off-diagonal elements having partial correlation should be very small. 
Correlation Matrix

Correlation $\mid$ A-CTFIN-

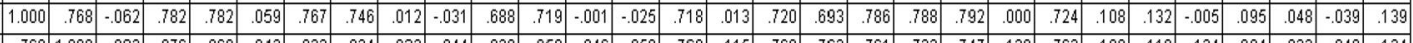

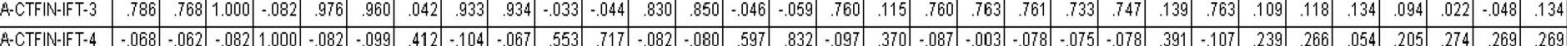

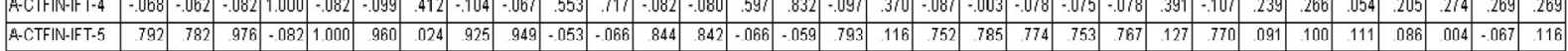

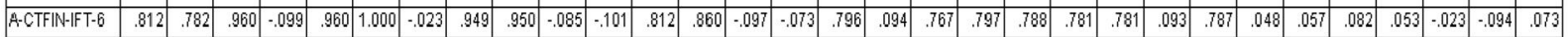

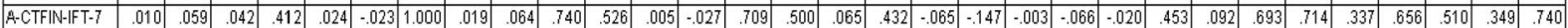

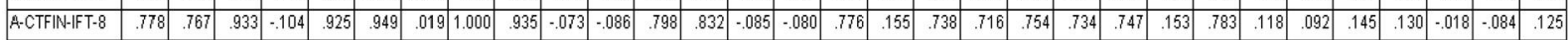

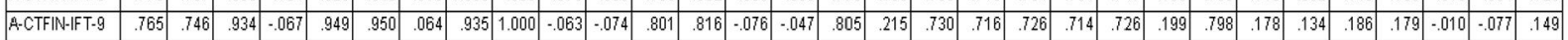

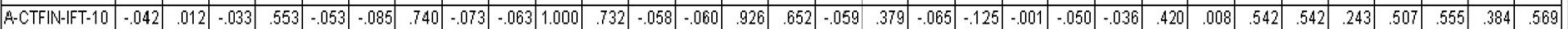

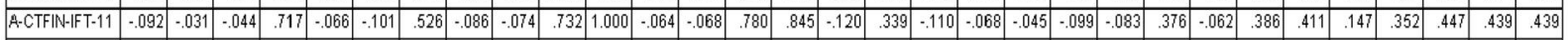

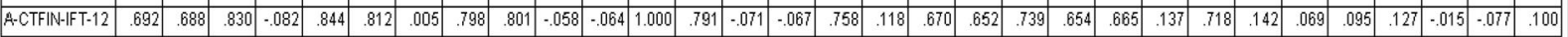

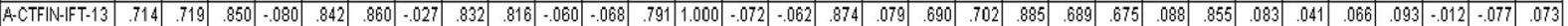

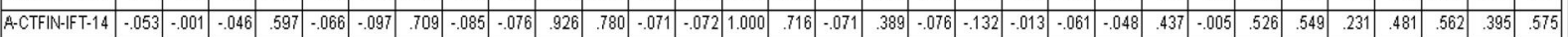

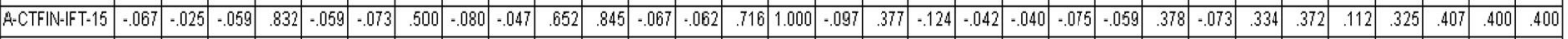

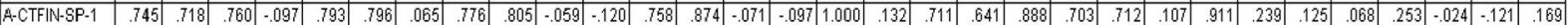

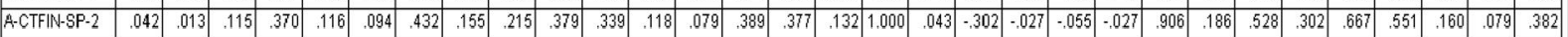

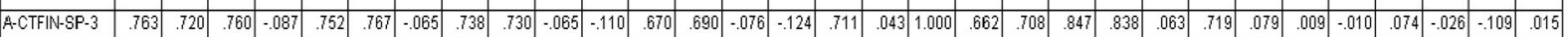

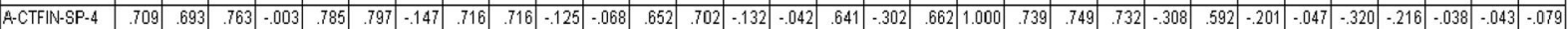

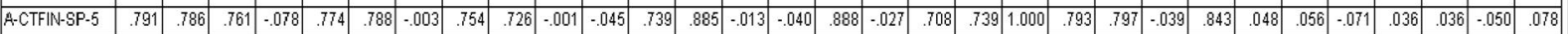

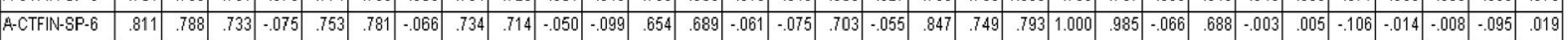

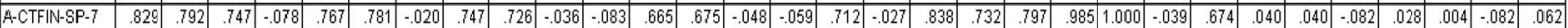

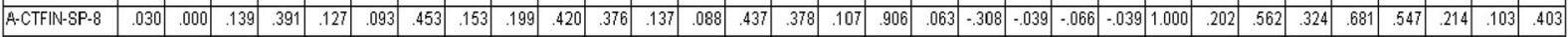

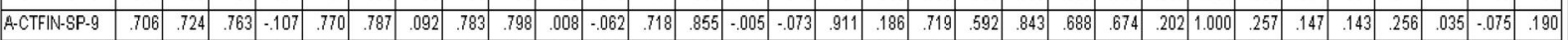

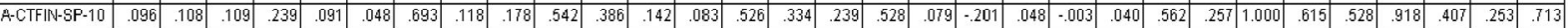

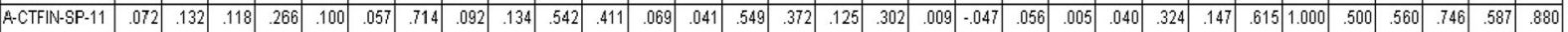

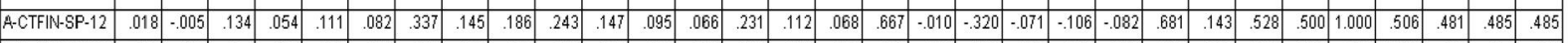

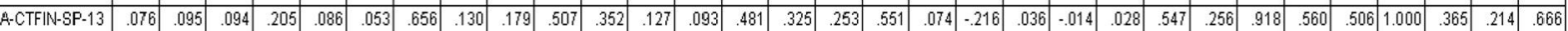

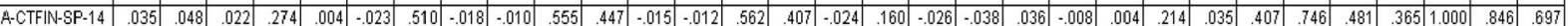

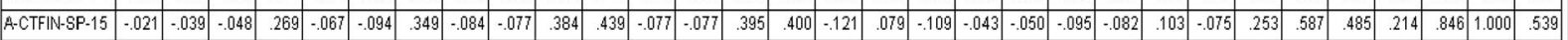

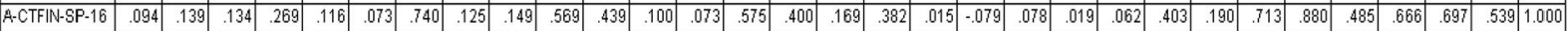

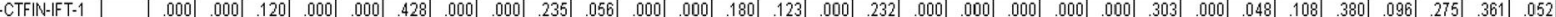

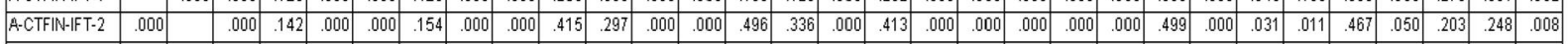

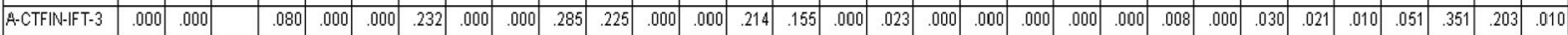

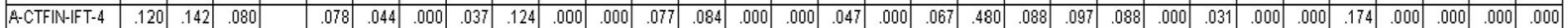

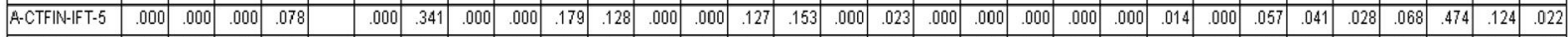

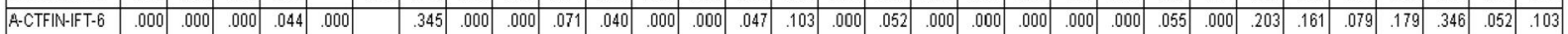

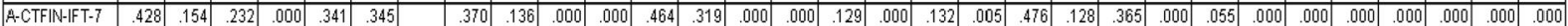

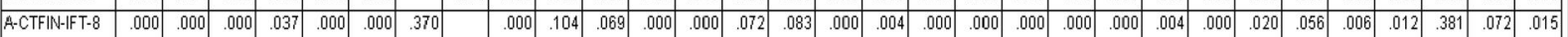
\begin{tabular}{|l|llllllllllllllllllllllllllllllllll}
\hline A-CTFIN-IFT-9 & .000 & .000 & .000 & .124 & .000 & .000 & .136 & .000 & & .137 & .099 & .000 & .000 & .095 & .207 & .000 & .000 & .000 & 000 & .000 & .000 & .000 & .000 & .000 & .001 & .010 & .001 & .001 & .431 & .090 & .005 \\
\hline AC
\end{tabular}

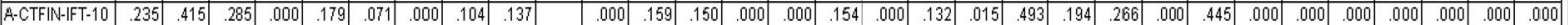

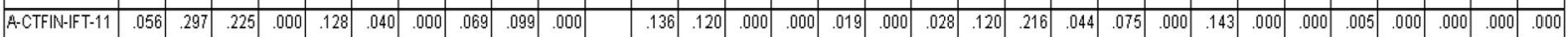
\begin{tabular}{|l|lllllllllllllllllllllllllllllllll}
\hline ACTFIN-IFT-12 & .000 & .000 & .000 & .077 & .000 & .000 & .464 & .000 & .000 & .159 & .136 & & .000 & .111 & .125 & .000 & .021 & .000 & .000 & .000 & .000 & .000 & .009 & .000 & .007 & .116 & .050 & .014 & .400 & .090 & .042 \\
\hline ACT
\end{tabular}

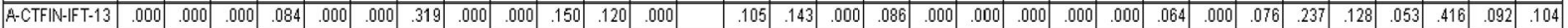

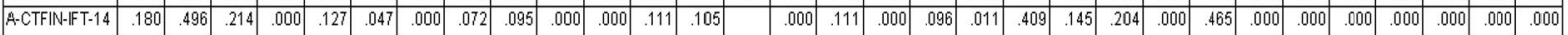

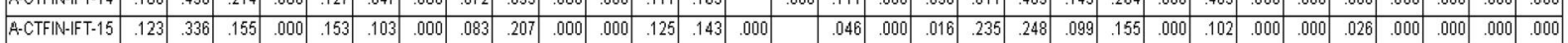

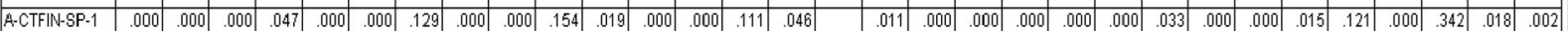

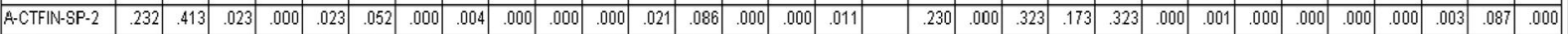

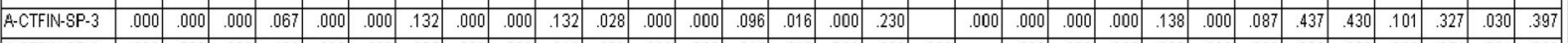

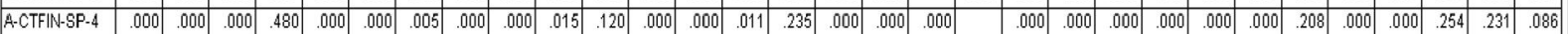

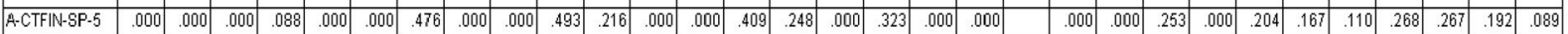

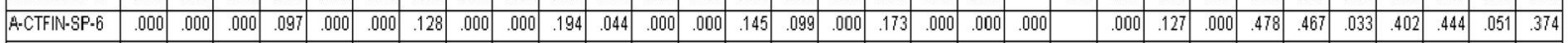

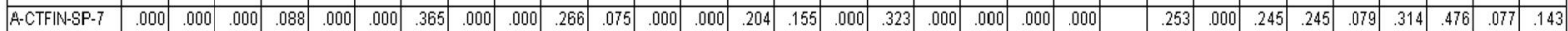

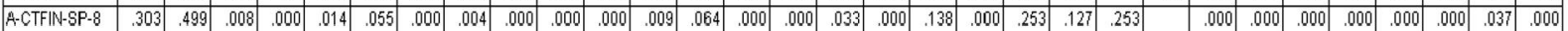

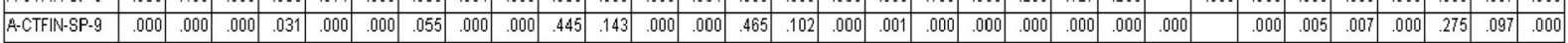

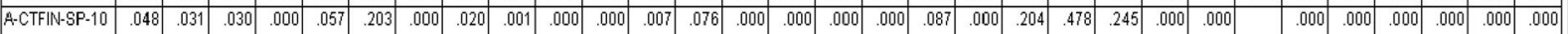

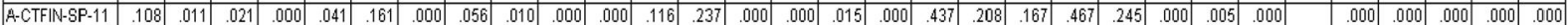

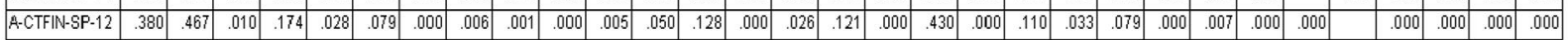

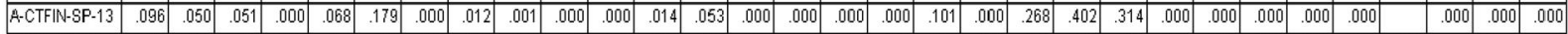

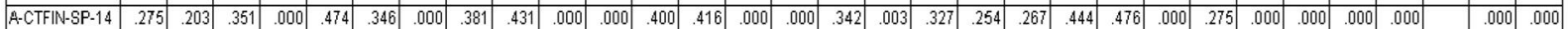

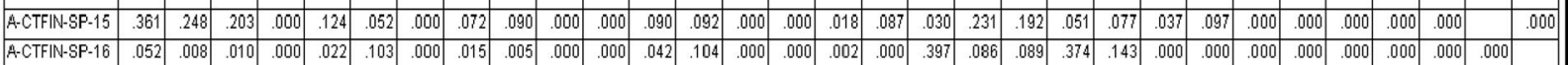
Determinant $=3.544 \mathrm{E}-023$

Mehran University Research Journal of Engineering \& Technology, Volume 37, No. 4, October, 2018 [p-ISSN: 0254-7821, e-ISSN: 2413-7219] 595 


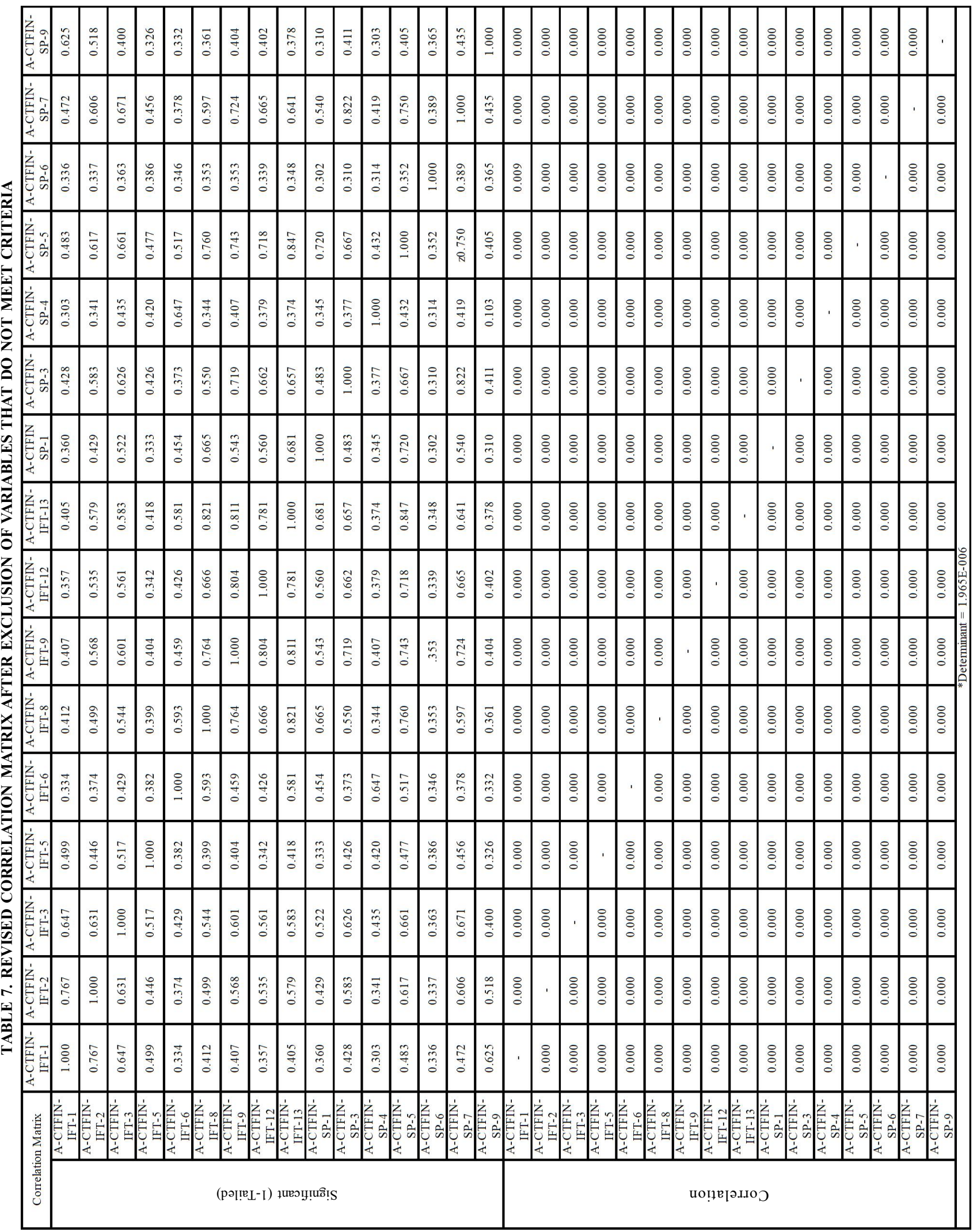

Mehran University Research Journal of Engineering \& Technology, Volume 37, No. 4, October, 2018 [p-ISSN: 0254-7821, e-ISSN: 2413-7219] 
Measure of Sampling Adequacy KMO/Bartlett's Test of Sphericity: In Table 8 the referenced tests is used to test the suitability of the respondent data for factor analysis (KMO and Bartlett's tests). Andy Field discussed that Kaiser proposed KMO value should lies between 0.8 and 0.9 to be considered as greater value, while minimum acceptable value of KMO equal to 0.5 or moderate value lies between 0.5 and 0.7 or good value lies between 0.7 and 0.8 . Whereas, superb value is considered as greater than 0.9 , provide confidence about adequacy of the size of the sample for factor analysis. Removal of variables should effect KMO statistics and likewise reexamine the matrix. $\mathrm{KMO}=0.908$ showing confidence about adequate sample size for factor analysis and Bartlett's test $\mathrm{p}<0.05=$ 0.00 . The significance test shows that R-matrix is not an identity matrix; therefore, some acceptable level of correlation does exist between variables which can be included in the analysis. Therefore, for suitable factor analysis the value of Bartlett's test of Sphericity should be significant ( $p<$ shows, the Bartlett's measure test of sphericity and the anti-image correlation matrix reveals relationship among different variables. The KMO statistics values for individual variables are produced on the diagonal (highlighted values greater than bare minimum value of 0.5 for all variables) of the anti-image correlation matrix. The values other than diagonal values (off-diagonal values) show small partial correlation between variables. The original correlation matrix is an identity matrix and Bartlett's measure tests the null hypothesis. Therefore, the result values show that except some exception there exist a small partial correlation between variables which means that R-matrix is not an identity matrix and the test attained bare minimum level of significance $(p<0.05)$. The Table 9 discussed the possibility to explore the variability in scores as far as the anti-image matrices is concern.
In Table 9, the research study explores the possibility of calculating a variance as the "variability in scores" for any given measures (common variance) and some of them would be specific to a particular measure (unique variance) and can be reliably attributed to only one measure. The presence of unique variance does not ignore the possibility of error or random variances. Therefore, a proportion of common variance present in a variable is known as the communality. A variable that has no random variance would have a communality of 1 ; likewise, a variable that shares none of its variance with any other variable would have a communality of 0 .

Step-2: How Factors can be Extracted? The literature review specified different methods of factors extraction: PCA Maximum Likelihood; PAF; Un-weighted least square; Generalized least square; Image factoring, Alpha factoring, and Canonical. PCA and PAF are used commonly in social sciences research studies. However, PCA is recommended in EFA, especially when no priori or theory or model exists to conduct research studies Pett et. al. [33]. The PCA works on the initial assumption that all variance is common, therefore, before extraction of communalities all variables have value equals to 1 , as a common variance. Extra unqualified variables are then discarded after extraction, therefore some information is lost. The retained factors can't explain all of the variances present in the data. SPSS output also shows components matrix before rotation, displaying all loadings less than 0.4 be suppressed in the output. Here the aim of the rotation is to segregate high loading items on one factor from the low loading items on the remaining factors; that is, simplifying the factor structure of a group of items to develop better understanding about the subject.

TABLE 8. RESULTS OF KMO \& BARTLETT'S TEST

\begin{tabular}{|c|c|c|}
\hline \multicolumn{2}{|c|}{ KMO and Bartlett's Test } & 000.908 \\
\hline \multirow{2}{*}{ Kaiser-Meyer-Olkin Measure of Sampling Adequacy } & 3847.772 \\
\cline { 2 - 3 } Bartlett's Test of Sphericity & Approximately Chi-Square & 120.000 \\
\cline { 2 - 3 } & Difference & 000.000 \\
\hline
\end{tabular}

Mehran University Research Journal of Engineering \& Technology, Volume 37, No. 4, October, 2018 [p-ISSN: 0254-7821, e-ISSN: 2413-7219] 
Product-Counterfeiting can be Controlled in Supply Chains of Automotive Parts Industry




Step-3: How to Determine Factor Extraction Criteria? There are various criteria available to researcher to simplify factor solution and produce scale uni-dimensionality. Hair et. al. [32] discussed that there exist no rule of thumb for a particular criteria for that matter, instead multiple criteria depending upon the circumstance may be used as appropriate and desirable (simultaneous multiple decision rule). The Scree test, Kaiser's criteria (Eigen value $>1$ rule), the cumulative percentage of variance extracted, and parallel analysis are suggested as multiple approaches used in factor extraction. Most peer reviewed publications apply multiple extraction techniques required for manuscripts.

Eigen Values $>1$ Rule and Cumulative Percentage of Variance: This may be considered as an area of disagreement using factor analysis tool in different areas of study: Psychology, Sociology, Humanities, and natural sciences studies. In Natural sciences factors are stopped when 95\% variances are explained. In Humanities, the explained variance is commonly as low as $50-60 \%$ (Hair et. al. [32]). To determine the linear component (factor, Eigen values and vector) within the dataset for R-matrix, the size of the magnitude of the of Eigen values determines which factor to be retained or discarded. The referenced list shows the Eigen values before and after extraction and rotation against each linear component (factor). There were 31 linear components before extraction within the dataset that was then filtered into 16 linear components for further analysis. SPSS extracted all factors with Eigen values greater than 1, which leaves 4 factors to clearly explain the definition (column labeled as "Extraction Sums of Squared Loading”). There is another column labeled "Rotation Sums of Squared Loadings" (showing Eigen values of the factors after rotation) brings optimization effect on the factor structure where relative importance of four factors are equalized. Before rotation, factor 1 accounted for considerably more variance than the remaining three Total Extracted Sums of Squared Loadings (8.532 compared to 1.422, 1.174, and 1.043), but after extraction it accounts for moderately adjusted values 7.615, 5.201, 3.265 and 2.022 as Total of Rotation Sums of Squared Loadings.

The Table 10 demonstrates the cumulative percentage of variance of $76.062 \%$ and total of 4 components (out of 16 components) having an Eigen value $>1$.

The SPSS output shows the Table 11 of communalities before and after extraction. The communality is the proportion of common variance within a variable. Thereby, SPSS has extracted four factors and exercised Kaiser's criterion that apply when there are less than 30 variables or communalities after extraction are greater than 0.7 or when the sample size exceed 250 or the average communality is greater than 0.6. The SPSS output shows communalities where most of the variables have values greater than 0.7 and no values found less than 0.5 . The average of the communalities can be calculated by summing up all extracted values and divided by number of variables. The average value then becomes $12171 / 16=0.7606875$. On both grounds the values found to be greater than 0.5 , so Kaiser's rule applies here, especially in situations where sample size is small.

Scree Test: The test is subjective and graphic where researchers' judgement is required. Thus disagreement may lead to an open debate about which factors to be retained and which factors to be discarded (Straub [24] and Tabachnick et. al. [28]). This disagreement and subjectivity require solution in case of large sample size (higher than N:P ratio 3:1) together with higher values of communalities. The name of the Scree test is given by Cattell [34] due to its graphical presentation, quoted an

Mehran University Research Journal of Engineering \& Technology, Volume 37, No. 4, October, 2018 [p-ISSN: 0254-7821, e-ISSN: 2413-7219] 
Product-Counterfeiting can be Controlled in Supply Chains of Automotive Parts Industry

example as being the rock debris lying at the bottom of the mountain. Two steps are involved during inspection and interpretation of Scree Plot, which are: (1) a straight line should be drawn through smaller Eigen values where a curve tilt may be observed leading to visual similarities just like rock debris at the foot of the mountain; (2) to determine the point of inflexion where the point above a tilt or a break (not including the brake itself) up-till then items/factors can be retained.

Fig.1 shows from beginning to the tail off after three factors of the Scree Plot, yet there observed another drop after fourth factor before a stable plateau is reached. Therefore, it is properly justified retaining either two or four factors. The following Scree plot shows 4 factors result where Eigen values have produced a departure from linearity.
TABLE 11. EXTRACTION METHOD EXPLAINED

\begin{tabular}{|c|c|c|}
\hline \multicolumn{3}{|c|}{ Communalities } \\
\hline Dimensions & Initial & Extraction \\
\hline A-CTFIN-IFT-1 & \multirow{16}{*}{1.000} & 0.870 \\
\hline A-CTFIN-IFT-2 & & 0.740 \\
\hline A-CTFIN-IFT-3 & & 0.684 \\
\hline A-CTFIN-IFT-5 & & 0.570 \\
\hline A-CTFIN-IFT-6 & & 0.783 \\
\hline A-CTFIN-IFT- 8 & & 0.805 \\
\hline A-CTFIN-IFT-9 & & 0.828 \\
\hline A-CTFIN-IFT-12 & & 0.777 \\
\hline A-CTFIN-IFT-13 & & 0.869 \\
\hline A-CTFIN-SP-1 & & 0.673 \\
\hline A-CTFIN-SP-3 & & 0.709 \\
\hline A-CTFIN-SP-4 & & 0.801 \\
\hline A-CTFIN-SP-5 & & 0.831 \\
\hline A-CTFIN-SP- 6 & & 0.818 \\
\hline A-CTFIN-SP-7 & & 0.733 \\
\hline A-CTFIN-SP-9 & & 0.680 \\
\hline
\end{tabular}

TABLE 10. EXTRACTION METHOD: PRINCIPAL COMPONENT ANALYSIS (TOTAL VARIANCE EXPLAINED)

\begin{tabular}{|c|c|c|c|c|c|c|c|}
\hline \multicolumn{8}{|c|}{ Total Variance Explained } \\
\hline \multirow{2}{*}{ Componen } & \multicolumn{3}{|c|}{ Initial Eigenvalues } & \multicolumn{3}{|c|}{ Extraction Sums of Squared Loadings } & \multirow{2}{*}{$\begin{array}{c}\begin{array}{c}\text { Rotation Sums } \\
\text { of Squared } \\
\text { Loadings* }\end{array} \\
\text { Total }\end{array}$} \\
\hline & Total & Variance $(\%)$ & Cumulative $(\%)$ & Total & Variance (\%) & Cumulative (\%) & \\
\hline 1 & 8.532 & 53.326 & 53.326 & 8.532 & 53.326 & 53.326 & 7.615 \\
\hline 2 & 1.422 & 8.885 & 62.211 & 1.422 & 8.885 & 62.211 & 5.201 \\
\hline 3 & 1.174 & 7.335 & 69.546 & 1.174 & 7.335 & 69.546 & 3.265 \\
\hline 4 & 1.043 & 6.516 & 76.062 & 1.043 & 6.516 & 76.062 & 2.022 \\
\hline 5 & 0.657 & 4.105 & 80.167 & - & - & - & - \\
\hline 6 & 0.566 & 3.538 & 83.705 & - & - & - & - \\
\hline 7 & 0.506 & 3.161 & 86.866 & - & - & - & - \\
\hline 8 & 0.458 & 2.860 & 89.726 & - & - & - & - \\
\hline 9 & 0.332 & 2.077 & 91.803 & - & - & - & - \\
\hline 10 & 0.325 & 2.034 & 93.837 & - & - & - & - \\
\hline 11 & 0.242 & 1.510 & 95.347 & - & - & - & - \\
\hline 12 & 0.212 & 1.327 & 96.674 & - & - & - & - \\
\hline 13 & 0.174 & 1.088 & 97.762 & - & - & - & - \\
\hline 14 & 0.143 & 0.896 & 98.658 & - & - & - & - \\
\hline 15 & 0.128 & 0.797 & 99.455 & - & - & - & - \\
\hline 16 & 0.087 & 0.545 & 100.000 & - & - & - & - \\
\hline
\end{tabular}

Mehran University Research Journal of Engineering \& Technology, Volume 37, No. 4, October, 2018 [p-ISSN: 0254-7821, e-ISSN: 2413-7219] 
Parallel Analysis: This technique is very helpful in extracting factors, that is, decision making about how many factors to retain (Fig. 2). Gorsuch [35] discussed that the parallel analysis technique although used rarely showed some application and usefulness. In this technique, actual Eigen values can be compared with randomly generated Eigen Values. Here, we retained those factors whose actual Eigen values exceed from randomly generated Eigen values. Therefore, best fit solution will be extracted and factors structure is finalized at this stage.

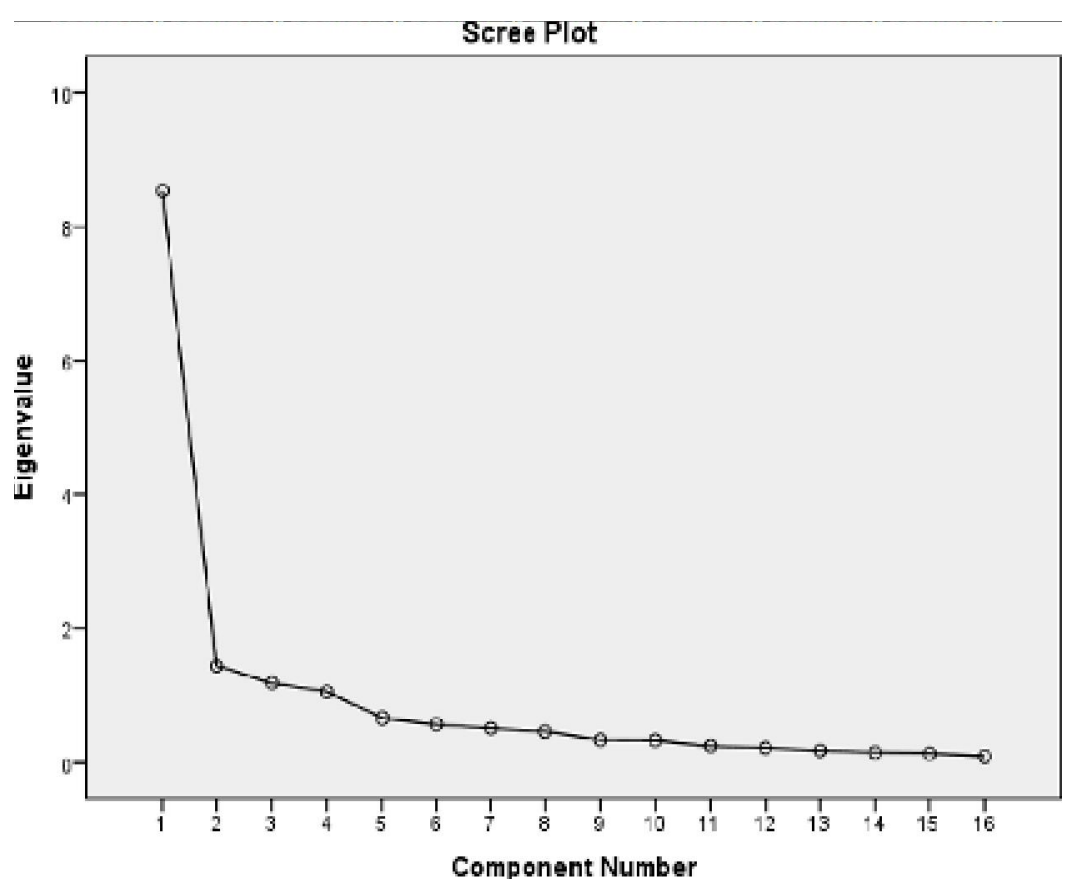

FIG. 1. SCREE PLOT (EIGEN VALUE AT A POINT DEPART FROM LINEARITY

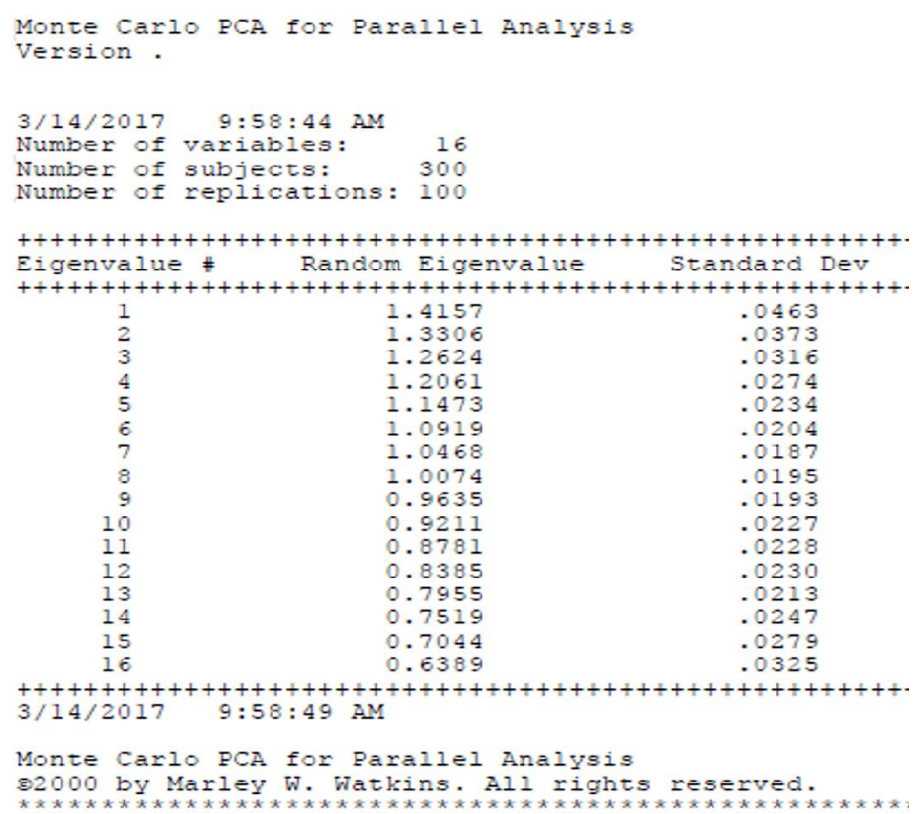

FIG. 2. PCA FOR PARALLEL ANALYSIS (MONTE CARLO METHOD) 
The data collected from total variance is explained by 4 components $(8.532,1.422,1.174,1.043)$ in which 2 components $(8.532,1.422)$ are greater than randomly generated Eigen values $(1.4157,1.3306)$ respectively. In this connection it is also observed that other two components $(1.174,1.043)$ are lower than randomly generated Eigen values $(1.2624,1.2061)$ respectively. Therefore, first two components are extracted for best fit solution that recommended final factors structure. However, contextual references supported theoretical concept for 4 components as best fit to make the most conceptual sense and thus surpasses the suggested extraction during parallel analysis for final structure.

Step-4: Selection of Rotational Method: When data have relations with more than one factor we apply rotational method so that clear demarcation of minimum and maximum item loadings can be observed. This clear and simplified version can be easily interpreted and can help the decision making process. There are two common rotation techniques: Orthogonal rotation and oblique rotation. Researchers have several methods to choose from both rotations options (orthogonal varimax/ quartimax or oblique olbimin/promax). The rational technique produces factor structures that are uncorrelated. Whereas, oblique rotation produces factors that are correlated for producing more accurate results for research work involving human behaviors or where data does not meet priori assumptions. Here, the main question is whether a variable might relate to more than one factor or not. Rotation produces a more interpretable and simplified solution. Thus, any rotated solution can be used which can provide factorial stability (conceptually \& intuitively) and best fit. It is to be noted that there may observe some situations where items might load on several factors and seems not conceptually fit according to the logical factor structure. So, items can then be reexamined which one to retain and which one to discard.

Method-1: Factor Extraction (Oblique Rotation with Four Factors: When an oblique rotation is conducted, the factor matrix is split into two matrices: (1) Pattern Matrix; (2) Structure Matrix. The pattern matrix contains the factor loadings and is comparable to the factor matrix that was interpreted for the orthogonal rotation. The structure matrix is a product of the pattern matrix and the matrix containing the correlation coefficient between the factors. Andy Field discussed that most researchers interpret the pattern matrix due to its simplicity. In fact, there are situations where values in the pattern matrix are suppressed because of relationships between the factors. Then structure matrix is useful for double check (Table 12).

After completing the third step, four factors are emerged in the pattern matrix where few loading are too small to be displayed. Factor-1 represents "Contractual Binding with the Suppliers", Factor 2 represents "Campaign against Product Counterfeiting", Factor 3 represents "Create Awareness against Counterfeiting", and Factor 4 represents "Formulate Programs to streamline surveillance efforts against product counterfeiting". On the contrary, the Structure Matrix differs in that "shared variance" which is another important aspect that should not be ignored. More complicated results produced from the Structure Matrix because of the relationship among Factors 1, 2, and 3 and Factors 1, 2 and 4. Therefore, the Pattern Matrix is preferable for clearer interpretive reasons: because it contains information about the unique contribution of a variable to a factor. 
The final portion of the SPSS output is the correlation matrix between factors where reference was made to Structure Matrix for further discussion. The Structure
Matrix indicates that Factor 1 and 2 noticeably interrelated to each other but Factor 3 and 4 have no relation with each other (Table 13).

\section{TABLE 12. DETAILS OF FACTOR EXTRACTION (OBLIQUE ROTATION WITH FOUR FACTORS)}

\begin{tabular}{|c|c|c|c|c|}
\hline \multicolumn{5}{|c|}{ Pattern Matrix* } \\
\hline \multirow{2}{*}{ Dimensions } & \multicolumn{4}{|c|}{ Component } \\
\hline & 1 & 2 & 3 & 4 \\
\hline A-CTFIN-IFT-13 & 0.925 & - & - & - \\
\hline A-CTFIN-IFT- 8 & 0.891 & - & - & - \\
\hline A-CTFIN-IFT-12 & 0.828 & - & - & - \\
\hline A-CTFIN-IFT-9 & 0.817 & - & - & - \\
\hline A-CTFIN-SP-1 & 0.805 & - & - & - \\
\hline A-CTFIN-SP-5 & 0.799 & - & - & - \\
\hline A-CTFIN-SP-7 & 0.586 & - & - & - \\
\hline A-CTFIN-SP-3 & 0.582 & - & - & - \\
\hline A-CTFIN-IFT-1 & - & 0.952 & - & - \\
\hline A-CTFIN-SP-9 & - & 0.779 & - & - \\
\hline A-CTFIN-IFT-2 & - & 0.697 & - & - \\
\hline A-CTFIN-IFT-5 & - & 0.511 & 0.463 & - \\
\hline A-CTFIN-IFT-3 & - & 0.491 & - & - \\
\hline A-CTFIN-SP-4 & - & - & 0.848 & - \\
\hline A-CTFIN-IFT-6 & - & - & 0.725 & - \\
\hline A-CTFIN-SP-6 & - & - & - & 0.900 \\
\hline \multicolumn{5}{|c|}{ Structure Matrix } \\
\hline A-CTFIN-IFT-13 & 0.931 & 0.462 & - & - \\
\hline A-CTFIN-SP-5 & 0.900 & 0.560 & 0.429 & - \\
\hline A-CTFIN-IFT-9 & 0.881 & 0.487 & - & 0.431 \\
\hline A-CTFIN-IFT-8 & 0.880 & 0.431 & 0.408 & - \\
\hline A-CTFIN-IFT- 12 & 0.853 & 0.439 & - & 0.417 \\
\hline A-CTFIN-SP-7 & 0.784 & 0.615 & - & 0.443 \\
\hline A-CTFIN-SP-1 & 0.782 & - & - & - \\
\hline A-CTFIN-SP-3 & 0.758 & 0.571 & - & 0.492 \\
\hline A-CTFIN-IFT-1 & 0.427 & 0.920 & - & - \\
\hline A-CTFIN-IFT-2 & 0.601 & 0.831 & - & - \\
\hline A-CTFIN-SP-9 & 0.420 & 0.778 & - & - \\
\hline A-CTFIN-IFT-3 & 0.658 & 0.719 & 0.463 & - \\
\hline A-CTFIN-IFT-5 & 0.405 & 0.611 & 0.572 & - \\
\hline A-CTFIN-SP-4 & 0.405 & - & 0.879 & - \\
\hline A-CTFIN-IFT-6 & 0.568 & - & 0.833 & - \\
\hline A-CTFIN-SP-6 & - & - & - & 0.900 \\
\hline
\end{tabular}

Mehran University Research Journal of Engineering \& Technology, Volume 37, No. 4, October, 2018 [p-ISSN: 0254-7821, e-ISSN: 2413-7219] 
The "Component Correlation Matrix" shows that existing correlation indicates that a construct measured can be interrelated. If the constructs were independent then oblique rotation do exists to provide an identical solution to an orthogonal rotation and the "Component Correlation Matrix" should then be an Identity Matrix, having correlation coefficient equals to zero. Therefore, Tables 14-15 show that the final matrix rejects the presence of factors' independence in the data and confirms the presence of interrelationship between factors. This means that the "Component Correlation Matrix" is not an Identity Matrix and considers obliquely rotated solution more meaningful as compare to orthogonal rotation.

Method-2: Factor Extraction (Orthogonal Varimax Rotation with Four Factors): The Rotated Component Matrix presents the four factors after Varimax Rotation. Identify what items loaded on each of the four components. The clustering of the items in each components means some meaning should be given to the concerned component. Here the meaning to first factor is related to the firm's decision in situation where counterfeits' infiltrate in supply chain (Campaign against product counterfeiting). The second factor is related to the firm's decision about Contractual Binding with supplier in case infiltration of suspected products/components takes place in different phases of operations (Contractual Binding with supplier). The third factor is related to the firm's decision about Creating Awareness among practitioners, authorities and academia in relation to Product Counterfeiting. The fourth factor is related to Formulate Programs to streamline surveillance efforts against product counterfeiting.

The rotated matrix in Tables 14-15 show several important considerations about the format of the matrix. First, factor loading less than 0.4 have not been displayed showing substantive value for complete interpretation (cited in Andi Field's book "Discovering Statistics Using SPSS"). Second, the variables are listed in the order of size of their factor loadings. A comparison (based on SPSS output) can be made between a Rotated Component Matrix and an un-rotated Component Matrix. There exist situations of uneven distribution of item loadings where some variables loaded highly and some variables did not get the right loadings. Therefore, application of the rotation technique of the factor structure has clarified context and makes interpretation possible. The final part of SPSS output is the Component Transformation Matrix which provides information about the degree to which the factors were rotated to obtain a solution. If no rotation were necessary, this matrix would be an Identity Matrix. If orthogonal rotation were completely appropriate then symmetrical matrix (same values below and above the diagonal) was expected. Therefore, the referenced matrix is found non-symmetrical which made orthogonal rotated solution meaningless and considers obliquely rotated solution more meaningful.

TABLE 13. DETAILS OF COMPONENT CORRELATION MATRIX

\begin{tabular}{|c|c|c|c|c|}
\hline \multicolumn{5}{|c|}{ Component Correlation Matrix } \\
\hline Component & 1 & 2 & 3 & 4 \\
\hline 1 & 1.000 & 0.508 & 0.387 & 0.241 \\
\hline 2 & 0.508 & 1.000 & 0.240 & 0.217 \\
\hline 3 & 0.387 & 0.240 & 1.000 & 0.096 \\
\hline 4 & 0.241 & 0.217 & 0.096 & 1.000 \\
\hline
\end{tabular}

Mehran University Research Journal of Engineering \& Technology, Volume 37, No. 4, October, 2018 [p-ISSN: 0254-7821, e-ISSN: 2413-7219] 
Product-Counterfeiting can be Controlled in Supply Chains of Automotive Parts Industry

TABLE 14. DETAILS OF FACTOR EXTRACTION (ORTHOGONAL VARIMAX ROTATION WITH FOUR FACTORS)

\begin{tabular}{|c|c|c|c|c|}
\hline \multicolumn{5}{|c|}{ Rotated Component Matrix* } \\
\hline \multirow{2}{*}{ Dimensions } & \multicolumn{4}{|c|}{ Component } \\
\hline & 1 & 2 & 3 & 4 \\
\hline A-CTFIN-IFT-13 & 0.872 & - & - & - \\
\hline A-CTFIN-IFT-8 & 0.833 & - & - & - \\
\hline A-CTFIN-SP-5 & 0.800 & - & - & - \\
\hline A-CTFIN-IFT-9 & 0.798 & - & - & - \\
\hline A-CTFIN-IFT-12 & 0.790 & - & - & - \\
\hline A-CTFIN-SP-1 & 0.747 & - & - & - \\
\hline A-CTFIN-SP-7 & 0.646 & 0.430 & . & . \\
\hline A-CTFIN-SP-3 & 0.631 & - & - & - \\
\hline A-CTFIN-IFT-1 & - & 0.889 & - & - \\
\hline A-CTFIN-SP-9 & - & 0.760 & - & - \\
\hline A-CTFIN-IFT-2 & - & 0.733 & - & - \\
\hline A-CTFIN-IFT-3 & 0.451 & 0.576 & - & - \\
\hline A-CTFIN-IFT-5 & - & 0.519 & 0.509 & - \\
\hline A-CTFIN-SP-4 & - & - & 0.844 & - \\
\hline A-CTFIN-IFT-6 & 0.429 & - & 0.769 & - \\
\hline A-CTFIN-SP-6 & - & - & - & 0.888 \\
\hline \multicolumn{5}{|c|}{ Component Matrix** } \\
\hline A-CTFIN-SP-5 & 0.890 & - & - & - \\
\hline A-CTFIN-IFT-13 & 0.872 & - & - & - \\
\hline A-CTFIN-IFT-9 & 0.859 & - & - & - \\
\hline A-CTFIN-SP-7 & 0.834 & - & - & - \\
\hline A-CTFIN-IFT-12 & 0.814 & - & - & - \\
\hline A-CTFIN-IFT-8 & 0.813 & - & - & - \\
\hline A-CTFIN-SP-3 & 0.801 & - & - & - \\
\hline A-CTFIN-IFT-3 & 0.792 & - & - & - \\
\hline A-CTFIN-IFT-2 & 0.757 & 0.401 & - & . \\
\hline A-CTFIN-SP-1 & 0.714 & - & - & - \\
\hline A-CTFIN-IFT-1 & 0.650 & 0.608 & - & - \\
\hline A-CTFIN-IFT-6 & 0.620 & - & 0.504 & - \\
\hline A-CTFIN-IFT-5 & 0.594 & - & 0.407 & - \\
\hline A-CTFIN-SP-9 & 0.541 & 0.584 & - & \\
\hline A-CTFIN-SP-4 & 0.548 & - & 0.612 & - \\
\hline A-CTFIN-SP-6 & - & - & - & 0.819 \\
\hline Extraction Metho & nent $A$ & $\begin{array}{l}\text { : Vari } \\
\text { onents }\end{array}$ & zation, & 5 iterations \\
\hline
\end{tabular}

TABL 15. DETAILS OF COMPONENT CORRELATION MATRIX

\begin{tabular}{|c|c|c|c|c|}
\hline \multicolumn{5}{|c|}{ Component Transformation Matrix } \\
\hline Component & 1 & 2 & 3 & 4 \\
\hline 1 & 0.759 & 0.504 & 0.356 & 0.207 \\
\hline 2 & -0.423 & 0.847 & -0.321 & 0.039 \\
\hline 3 & -0.423 & 0.128 & 0.863 & -0.245 \\
\hline 4 & -0.258 & -0.113 & 0.159 & 0.946 \\
\hline \multicolumn{2}{|c|}{ Extraction Method: Principal Component Analysis, Rotation Method: Varimax with Kaiser Normalization. } \\
\hline
\end{tabular}

Mehran University Research Journal of Engineering \& Technology, Volume 37, No. 4, October, 2018 [p-ISSN: 0254-7821, e-ISSN: 2413-7219] 
Step-5: Interpretation and Labeling: The meaningfulness of latent factors is ultimately dependent upon researcher definition. Traditionally, two or more variables loads on a factor should give meaningful interpretation and then give that factor a name or theme or label for further usage. The reason for thorough and systematic factor analysis is to isolate items with high loadings in the resultant pattern matrices. In other words, it is a search to find those factors that are taken together explaining the majority of the responses. Here, researcher decision is meaningful with these factors to retain and then operationalized and descriptively labeled. Therefore, it is important that these labels or constructs reflect the theoretical and conceptual intent. For further interpretation of the results, the study of the reliability of scale is performed.

\section{CHECKING THE RELIABILITY OF SCALE}

\subsection{Overall Scale Internal Consistency}

Checked the Case Processing Summary table for correct number of cases and Reliability Statistics table for correct number of items. Inter-Item-Correlation Matrix table displayed all positive values for the Corrected-ItemCorrelation values.

All Cronbach $\alpha$ values shown in Reliability Statistics tables are $0.947,0.854$, and 0.785 , for factor 1,2 , and 3 respectively, suggesting very good overall internal consistency reliability for the scale. The fourth component A-CTFIN-SP-6 represented an independent single item component. The reliability statistics shows that none of the items representing capability of increasing reliability if they are deleted. Therefore, table shows that all items are positively contributing to the overall scale reliability.
Values in the Inter-Item-Correlation Matrix and the ItemTotal Statistics table indicate the degree to which each item is correlated with the total score. Higher values $(>0.3)$ indicate that the item is measuring correctly from the scale.

The mean Inter-Item Correlation value suggests quite a moderate overall relationship among the items.

\subsection{Scale Reliability Analysis}

The item-total statistics table shows that what the Cronbach $\alpha$ value would be if that item was deleted. This ensures the reliability of the questionnaire at a particular stage where no item should cause a substantial decrease in $\alpha$. As greater values than 0.7 is seen as a good Cronbach $\alpha$ value, therefore, all Cronbach $\alpha$ values should be around 0.8 or higher. The inter-item correlations and covariances provide with correlation coefficients and averages for items on the scale. In a reliable scale all items should correlate with the total. Tables 16-24 show that all items according to the factors have values greater than 0.3 which means that a particular item does correlate very well with the overall scale. Therefore, items with low correlations may have to be dropped, which are none so far.

The overall Cronbach $\alpha$ value is 0.947 , and none of the items would increase the reliability if they were deleted. This indicates that all items are positively contributing to the overall reliability. The overall Cronbach $\alpha$ value is 0.947 is also excellent because it is above 0.8 and indicates good reliability.

The overall Cronbach $\alpha$ value is 0.854 , and none of the items would increase the reliability if they were deleted. This indicates that all items are positively contributing to the overall reliability. The overall Cronbach's $(\alpha)$ is 0.853 is also excellent because it is above 0.8 and indicates good reliability. 
The overall Cronbach $\alpha$ value is 0.786 , and none of the items would increase the reliability if they were deleted. This indicates that all items are positively contributing to the overall reliability. The overall Cronbach $\alpha$ value is 0.786 is also Good because it is above 0.7 and indicates good reliability.

TABLE 16. FACTOR-1; DETAILS OF INTER-ITEM CORRELATION MATRIX

\begin{tabular}{|c|c|c|c|c|c|c|c|c|}
\hline \multicolumn{10}{|c|}{$\begin{array}{c}\text { Factor-1: Inter-Item Correlation Matrix } \\
\text { with Suppliers }\end{array}$} & $\begin{array}{c}\text { A-CTFIN- } \\
\text { IFT-8 }\end{array}$ & $\begin{array}{c}\text { A-CTFIN- } \\
\text { IFT-9 }\end{array}$ & $\begin{array}{c}\text { A-CTFIN- } \\
\text { IFT-12 }\end{array}$ & $\begin{array}{c}\text { A-CTFIN- } \\
\text { IFT-13 }\end{array}$ & $\begin{array}{c}\text { A-CTFIN- } \\
\text { SP-1 }\end{array}$ & $\begin{array}{c}\text { A-CTFIN- } \\
\text { SP-3 }\end{array}$ & $\begin{array}{c}\text { A-CTFIN- } \\
\text { SP-5 }\end{array}$ & $\begin{array}{c}\text { A-CTFIN- } \\
\text { SP-7 }\end{array}$ \\
\hline A-CTFIN-IFT-8 & 1.000 & 0.764 & 0.666 & 0.821 & 0.665 & 0.550 & 0.760 & 0.597 \\
\hline A-CTFIN-IFT-9 & 0.764 & 1.000 & 0.804 & 0.811 & 0.543 & 0.719 & 0.743 & 0.724 \\
\hline A-CTFIN-IFT-12 & 0.666 & 0.804 & 1.000 & 0.781 & 0.560 & 0.662 & 0.718 & 0.665 \\
\hline A-CTFIN-IFT-13 & 0.821 & 0.811 & 0.781 & 1.000 & 0.681 & 0.657 & 0.847 & 0.641 \\
\hline A-CTFIN-SP-1 & 0.665 & 0.543 & 0.560 & 0.681 & 1.000 & 0.483 & 0.720 & 0.540 \\
\hline A-CTFIN-SP-3 & 0.550 & 0.719 & 0.662 & 0.657 & 0.483 & 1.000 & 0.667 & 0.822 \\
\hline A-CTFIN-SP-5 & 0.760 & 0.743 & 0.718 & 0.847 & 0.720 & 0.667 & 1.000 & 0.750 \\
\hline A-CTFIN-SP-7 & 0.597 & 0.724 & 0.665 & 0.641 & 0.540 & 0.822 & 0.750 & 1.000 \\
\hline
\end{tabular}

TABLE 17. FACTOR-1; DETAILS OF ITEM-TOTAL STATISTICS

\begin{tabular}{|c|c|c|c|c|c|}
\hline \multicolumn{5}{|c|}{ Factor-1: Item-Total Statistics } \\
\hline Contractual Binding with Suppliers & $\begin{array}{c}\text { Scale Mean if Item } \\
\text { Deleted }\end{array}$ & $\begin{array}{c}\text { Scale Variance if Item } \\
\text { Deleted }\end{array}$ & $\begin{array}{c}\text { Corrected Item-Total } \\
\text { Correlation }\end{array}$ & $\begin{array}{c}\text { Squared Multiple } \\
\text { Correlation }\end{array}$ & $\begin{array}{c}\text { Cronbach's Alpha if } \\
\text { Item Deleted }\end{array}$ \\
\hline A-CTFIN-IFT-8 & 30.03 & 19.665 & 0.802 & 0.736 \\
\hline A-CTFIN-IFT-9 & 29.97 & 19.788 & 0.857 & 0.940 \\
\hline A-CTFIN-IFT-12 & 30.05 & 19.626 & 0.808 & 0.937 \\
\hline A-CTFIN-IFT-13 & 30.04 & 19.166 & 0.882 & 0.940 \\
\hline A-CTFIN-SP-1 & 29.78 & 20.438 & 0.687 & 0.935 \\
\hline A-CTFIN-SP-3 & 29.98 & 19.742 & 0.754 & 0.567 \\
\hline A-CTFIN-SP-5 & 29.99 & 19.010 & 0.876 & 0.724 \\
\hline A-CTFIN-SP-7 & 29.95 & 19.704 & 0.788 & 0.947 \\
\hline
\end{tabular}

TABLE 18. FACTOR-1; DETAILS OF RELIABILITY STATISTICS

\begin{tabular}{|c|c|c|}
\hline \multicolumn{2}{|c|}{ Factor-1: Reliability Statistics } \\
\hline Cronbach's Alpha & Cronbach's Alpha Based on Standardized Items & No. of Items \\
\hline 0.947 & 0.947 & 8 \\
\hline
\end{tabular}

TABLE 19. FACTOR-2; DETAILS OF INTER-ITEM CORRELATION MATRIX

\begin{tabular}{|c|c|c|c|c|c|}
\hline \multicolumn{7}{|c|}{ Factor-2: Inter-Item Correlation Matrix } \\
\hline $\begin{array}{c}\text { Campaign against Product } \\
\text { Counterfeiting }\end{array}$ & A-CTFIN-IFT-1 & A-CTFIN-IFT-2 & A-CTFIN-IFT-3 & A-CTFIN-IFT-5 & A-CTFIN-SP-9 \\
\hline A-CTFIN-IFT-1 & 1.00 & 0.77 & 0.65 & 0.50 & 0.63 \\
\hline A-CTFIN-IFT-2 & 0.77 & 1.00 & 0.63 & 0.45 & 0.52 \\
\hline A-CTFIN-IFT-3 & 0.65 & 0.63 & 1.00 & 0.52 & 0.40 \\
\hline A-CTFIN-IFT-5 & 0.50 & 0.45 & 0.52 & 1.00 & 0.33 \\
\hline A-CTFIN-SP-9 & 0.63 & 0.52 & 0.40 & 0.33 & 1.00 \\
\hline
\end{tabular}

Mehran University Research Journal of Engineering \& Technology, Volume 37, No. 4, October, 2018 [p-ISSN: 0254-7821, e-ISSN: 2413-7219] 
Product-Counterfeiting can be Controlled in Supply Chains of Automotive Parts Industry

TABLE 20. FACTOR-2; DETAILS OF ITEM-TOTAL STATISTICS

\begin{tabular}{|c|c|c|c|c|c|}
\hline \multicolumn{7}{|c|}{ Factor-2: Item-Total Statistics } \\
\hline $\begin{array}{c}\text { Campaign against Product } \\
\text { Counterfeiting }\end{array}$ & $\begin{array}{c}\text { Scale Mean if Item } \\
\text { Deleted }\end{array}$ & $\begin{array}{c}\text { Scale Variance if Item } \\
\text { Deleted }\end{array}$ & $\begin{array}{c}\text { Corrected Item-Total } \\
\text { Correlation }\end{array}$ & $\begin{array}{c}\text { Squared Multiple } \\
\text { Correlation }\end{array}$ & $\begin{array}{c}\text { Cronbach's Alpha if } \\
\text { Item Deleted }\end{array}$ \\
\hline A-CTFIN-IFT-1 & 15.9 & 6.69 & 0.81 & 0.70 & 0.78 \\
\hline A-CTFIN-IFT-2 & 15.6 & 7.01 & 0.75 & 0.62 & 0.80 \\
\hline A-CTFIN-IFT-3 & 15.9 & 7.16 & 0.69 & 0.50 & 0.82 \\
\hline A-CTFIN-IFT-5 & 15.9 & 7.78 & 0.54 & 0.32 & 0.86 \\
\hline A-CTFIN-SP-9 & 15.3 & 8.28 & 0.56 & 0.40 & 0.85 \\
\hline
\end{tabular}

TABLE 21. FACTOR-2; DETAILS OF RELIABILITY STATISTICS

\begin{tabular}{|c|c|c|}
\hline \multicolumn{2}{|c|}{ Factor-2: Reliability Statistics } \\
\hline Cronbach's Alpha & Cronbach's Alpha Based on Standardized Items & No. of Items \\
\hline 0.854 & 0.853 & 5 \\
\hline
\end{tabular}

TABLE 22. FACTOR-3; DETAILS OF INTER-ITEM CORRELATION MATRIX

\begin{tabular}{|c|c|c|}
\hline \multicolumn{2}{|c|}{ Factor-3: Inter-Item Correlation Matrix } \\
\hline $\begin{array}{c}\text { Create Awareness against Product } \\
\text { Counterfeiting }\end{array}$ & A-CTFIN-IFT-6 & A-CTFIN-SP-4 \\
\hline A-CTFIN-IFT-6 & 1.000 & 0.647 \\
\hline A-CTFIN-SP-4 & 0.647 & 1.000 \\
\hline
\end{tabular}

TABLE 23. FACTOR-3; DETAILS OF ITEM-TOTAL STATISTICS

\begin{tabular}{|c|c|c|c|c|c|}
\hline \multicolumn{7}{|c|}{ Factor-3: Item-Total Statistics } \\
\hline $\begin{array}{c}\text { Create Awareness against Product } \\
\text { Counterfeiting }\end{array}$ & $\begin{array}{c}\text { Scale Mean if Item } \\
\text { Deleted }\end{array}$ & $\begin{array}{c}\text { Scale Variance if Item } \\
\text { Deleted }\end{array}$ & $\begin{array}{c}\text { Corrected Item-Total } \\
\text { Correlation }\end{array}$ & $\begin{array}{c}\text { Squared Multiple } \\
\text { Correlation }\end{array}$ & $\begin{array}{c}\text { Cronbach's Alpha if } \\
\text { Item Deleted }\end{array}$ \\
\hline A-CTFIN-IFT-6 & 4.4 & 0.5 & 0.6 & 0.4 & - \\
\hline A-CTFIN-SP-4 & 4.2 & 0.6 & 0.6 & 0.4 & - \\
\hline
\end{tabular}

TABLE 24. FACTOR-3; DETAILS OF RELIABILITY STATISTICS

\begin{tabular}{|c|c|c|}
\hline \multicolumn{2}{|c|}{ Factor-3: Reliability Statistics } \\
\hline Cronbach's Alpha & Cronbach's Alpha Based on Standardized Items & No. of Items \\
\hline 0.785 & 0.786 & 2 \\
\hline
\end{tabular}

\section{CONCLUSION}

The intent of this paper is to provide readership clear understanding about the existing common anticounterfeiting strategies to control product counterfeiting phenomenon in supply chain, under deceptive buying environment, for automotive industries in Pakistan. Conventional wisdom states that despite many options for executing the steps of EFA, the actual difference between them remains small, so it doesn't matter what method the practitioners chooses. A PCA was conducted on the 31 items/anti-counterfeiting strategies using SPSS version 20 and data analysis work was performed: first with Oblique rotation (Direct Oblimin) and then with Orthogonal rotation (Varimax) methods. The suitability of data for factor analysis was assessed prior to performing PCA. The correlation matrix, after inspection, revealed the presence of many coefficients of 0.3 and above. Correlation coefficients whose values exceed higher limit ( $>0.9$ ): to bring possible resolve to the issue

Mehran University Research Journal of Engineering \& Technology, Volume 37, No. 4, October, 2018 [p-ISSN: 0254-7821, e-ISSN: 2413-7219] 
of multi-collinearity in the data. The KMO measure confirms the adequacy of the sample size to continue with the analysis $(\mathrm{KMO}=0.908$, "Excellent" according to Field, 2009) where all KMO values for individual items are greater than 0.7 which are well above the acceptable limit of 0.5 (Field, 2009). Bartlett's test of sphericity X2 (120)= $3847.772, \mathrm{p}<0.001$, indicated that the correlations between items were found sufficiently large for PCA. For that matter, an initial analysis was run to obtain eigenvalues for each component in the data. Initially, four (4) components have eigenvalues over Kaiser's criterion of 1.0 and in combination (cumulative) explained $76.062 \%$ of the variance. An inspection of the Scree Plot revealed a clear break after the third component. But later on the Scree Plot was slightly ambiguous and showed inflexions that would justify retaining fourth component as well. The sample size of 300 respondents, the convergence of the scree plot and Kaiser's criterion focused on four components which will be retained in the final analysis. Referring to the analytical table-A1, the item that cluster on the same component suggest that Component 1 represents "Contractual binding with suppliers", Component 2 represents "Campaign against product counterfeiting", Component 3 represents "Create Awareness against counterfeiting", and Component 4 represents "Formulate Programs" to control product counterfeiting in supply chains for automotive industries in Pakistan. The fourth component represent a single component shows its presence for further analysis in the research model. The ANCT-INT construct is found to be a promising candidate for being conceptualized as an antecedent to the SCQM in the PhD thesis dissertation. The model discussed in the thesis affirms the direct and indirect positive impact of TQM on SCM and FSP. Therefore, some clear decision and rules apply to EFA emphasizing that clear decision sequencing and protocols are paramount in each investigation. Moreover, there are five steps EFA statistical technique which was found useful in contemplating the said research requirements. Futuristically, once an instrument has been developed using EFA, it is time to move to CFA to answer questions regarding validity of the instrument in certain population subgroups. CFA can allow researchers to test hypothesis via inferential techniques and can provide more informative analytical options.

\section{ACKNOWLEDGEMENT}

Believe you me it was not easy to do the research work of this nature with all responsibilities (office, family, etc.). At the start of the study I was bit nervous but with the passage of time I gained confidence and things became easier which made me committed to undergo such hectic exercise. First of all I would like to bow my head in gratitude to All Mighty Allah for all the blessings I got and then I would like to thank the Higher Education Commission (HEC) Pakistan, the Department and the University for commissioning this study on a topic of high strategic significance, not only with reference to Governments, Firms and Institutions but for national economic growth and development. Furthermore, I thank my Parents, friends and colleagues for their continued moral support in times of need, their patience during my busy hours, and especially, for their infinite support for my success.

\section{REFERENCES}

[1] OECD, "The Economic Impact of Counterfeiting", OECD, Paris, 1998.

[2] Automotive Marketing, "Parts Counterfeiting: The Problem that Won't Go Away”, US, 1998.

[3] OECD, "Current Conditions in Counterfeiting and Piracy", OECD, Paris, 2008.

[4] Green, R.T., and Smith, T., "Executive Insights: Countering Brand Counterfeiters", Journal of International Marketing, Volume 10, No. 4, pp. 39-106, US, 2002.

[5] OECD, "The Economic Impact of Counterfeiting and Piracy: Executive Summary”, OECD, Paris, 2005.

[6] Williams, B., Onsman, A., and Brown, T., "Exploratory Factor Analysis: A Five-Step Guide for Novices”, Journal of Paramedicine, Volume 8, No. 3, Australasian, 2010.

[7] Kieffer, K.M., "An Introductory Primer on the Appropriate Use of Exploratory and Confirmatory Factor Analysis", Research in the Schools, Volume 6, No. 2, pp.75-92, 1999. 
[8] Bodner, D.A., "Enterprise Modeling Framework for Counterfeit Parts in Defense Systems", Procedia Computer Science, Volume 36, pp. 425-431, 2014.

[9] Bodner, D.A., "Mitigating Counterfeit Part Intrusions with Enterprise Simulation", Procedia Computer Science, Volume 61, pp. 233-239, 2015.

[10] Santos, J.F., and Ribeiro, J.C., "An Exploratory Study of the Relationship between Counterfeiting and Culture", Tékhne-Revista de EstudosPolitécnicos, Volume 5-6, pp. 227-243, 2006.

[11] Staake, T.R., Thiesse, F., and Fleisch, E., "The Emergence of Counterfeit Trade: A Literature Review", European Journal of Marketing, Volume 43, pp. 320-349, 2009.

[12] Staake, T.R., Thiesse, F., and Fleisch, E., "Business Strategies in the Counterfeit Market", Journal of Business Research, 2011.

[13] D'Amato, I., and Papadimitriou, T., "Legitimate vs Illegitimate: the Luxury Supply Chain and Its Doppelganger", International Journal of Retail \& Distribution Management, Volume 41, No. 11/12, pp. 986-1007, 2013.

[14] Chaudhry, P.E., Zimmerman, A., "The Economics of Counterfeit Trade - Governments, Consumers, Pirates and Intellectual Property Rights”, Springer, Berlin, 2009.

[15] Chaudhry, P.E., Zimmerman, A., Peters, J.R., and Cordell, V.V., "Preserving Intellectual Property Rights: Managerial Insight into the Escalating Counterfeit Market Quandary", Business Horizons, Volume 52, No. 1, pp. 57-66, 2009.

[16] Eser, Z., Kurtulmusoglu, B., Bicaksiz, A., and Sumer, S. I., "Counterfeit Supply Chains", Procedia Economics and Finance, Volume 23, pp. 412-421, 2015.

[17] Yang, D., Sonmez, M., and Bosworth, D., "Intellectual Property Abuses: How Should Multinationals Respond?Long Range Planning”, Journal of World Business, Volume 37, No. 5, pp. 459-475, 2004.

[18] Stevenson, M., and Busby, J., "An Exploratory Analysis of Counterfeiting Strategies: Towards CounterfeitResilient Supply Chains", International Journal of Operations \& Production Management, Volume 35, No. 1, pp. 110-144, 2015.

[19] Wilcock, A.E., and Boys, K.A., "Reduce Product Counterfeiting: An Integrated Approach", Business Horizons, Volume 57, No. 2, pp. 279-288, 2014.

[20] Verma, S., Singh, A., Singh, D., and Laxmi, V., "Computer Forensics in IT Audit and Credit Card Fraud Investigationfor USB Devices", IEEE Conference on Computing for Sustainable Global Development, pp. 730-733, 2014.
CACP, "No Trade in Fakes Supply Chain Tool Kit", Property of the US Chamber of Commerce and Accenture, 2006.

[22] Alotaibi, N.D., "Extending and Validating the is-Impact Model in Saudi Arabia: Accounting for Computer Network Quality", Queensland University of Technology, Australia, 2012.

[23] Fink, A., and Kosecoff, J.B., "How to Conduct Surveys: A Step-by-Step Guide", Sage, Beverly Hills, CA, 1985.

[24] Straub, D.W., "Validating Instruments in MIS Research", MIS Quarterly, pp. 147-169, 1989.

[25] Bagozzi, R.P., "Causal Models in Marketing", Wiley, New York, USA, 1980.

[26] Fabrigar, L.R., Wegener, D.T., MacCallum, R.C., and Strahan, E.J., "Evaluating the Use of Exploratory Factor Analysis in Psychological Research", Psychological Methods, Volume 4, No. 3, pp. 272, 1999.

[27] MacCallum, R.C., Widaman, K.F., Zhang, S., and Hong, S., "Sample Size in Factor Analysis", Psychological Methods, Volume 4, No. 1, pp. 84, 1999.

[28] Tabachnick, B.G., Fidell, L.S., and Osterlind, S.J., "Using Multivariate Statistics”, Science \& Education, 2001.

[29] Comrey, L.A., and Lee, H.B., "A First Course in Factor Analysis”, Lawrence Erlbaum Associates, Hillside, NJ, 1992.

[30] Velicer, W.F., and Fava, J.L., "Time Series Analysis", Handbook of Psychology, 2003.

[31] Velicer, W.F., Prochaska, J.O., Fava, J.L., Norman, G.J., and Redding, C.A., "Smoking Cessation and Stress Management: Applications of the Transtheoretical Model", Homeostasis, Volume 38, pp. 216-233, 1998.

[32] Hair, J., Anderson, R.E., Tatham, R.L., and Black, W.C., "Multivariate Data Analysis", Prentice-Hall Inc, NJ, 1995.

[33] Pett, M.A., Lackey, N.R., and Sullivan, J.J., "Making Sense of Factor Analysis: The Use of Factor Analysis for Instrument Development in Health Care Research", Sage, 2003.

[34] Cattell, R.B., "The Scree Test for the Number of Factors", Multivariate Behavioral Research, Volume 1, No. 2, pp. 245-276, 1966.

[35] Gorsuch, R.L., "Exploratory Factor Analysis: Its Role in Item Analysis", Journal of Personality Assessment, Volume 68, No. 3, pp. 532-560, 1997. 